OPEN ACCESS

Edited by:

loannis Kourtzelis,

University of York, United Kingdom

Reviewed by:

Uday Kishore,

Brunel University London,

United Kingdom

Nardhy Gomez-Lopez,

Wayne State University, United States

${ }^{*}$ Correspondence:

Catherine A. Thornton

c.a.thornton@swansea.ac.uk

Specialty section: This article was submitted to

Molecular Innate Immunity,

a section of the journal

Frontiers in Immunology

Received: 16 September 2020 Accepted: 30 November 2020

Published: 14 January 2021

Citation:

Chambers M, Rees A, Cronin JG, Nair $M$, Jones $N$ and Thornton $C A$

(2021) Macrophage Plasticity in

Reproduction and Environmental

Influences on Their Function.

Front. Immunol. 11:607328.

doi: 10.3389/fimmu.2020.607328

\section{Macrophage Plasticity in Reproduction and Environmental Influences on Their Function}

\author{
Megan Chambers ${ }^{1}$, April Rees ${ }^{1}$, James G. Cronin ${ }^{1}$, Manju Nair ${ }^{2}$, Nicholas Jones ${ }^{1}$ \\ and Catherine A. Thornton ${ }^{1 *}$ \\ 1 Institute of Life Science, Swansea University Medical School, Swansea, United Kingdom, ${ }^{2}$ Maternity and Child Health, \\ Singleton Hospital, Swansea Bay University Health Board, Swansea, United Kingdom
}

Macrophages are key components of the innate immune system and exhibit extensive plasticity and heterogeneity. They play a significant role in the non-pregnant cycling uterus and throughout gestation they contribute to various processes underpinning reproductive success including implantation, placentation and parturition. Macrophages are also present in breast milk and impart immunomodulatory benefits to the infant. For a healthy pregnancy, the maternal immune system must adapt to prevent fetal rejection and support development of the semi-allogenic fetus without compromising host defense. These functions are dependent on macrophage polarization which is governed by the local tissue microenvironmental milieu. Disruption of this microenvironment, possibly by environmental factors of infectious and non-infectious origin, can affect macrophage phenotype and function and is linked to adverse obstetric outcomes, e.g. spontaneous miscarriage and preterm birth. Determining environmental influences on cellular and molecular mechanisms that control macrophage polarization at the maternal-fetal interface and the role of this in pregnancy complications could support approaches to alleviating adverse pregnancy outcomes.

Keywords: macrophage plasticity, uterus, placenta, breast milk, infection, obesity, air pollution, immunometabolism

\section{INTRODUCTION}

The establishment and ongoing success of pregnancy is reliant on finely tuned, dynamic maternal immune adaptations. It is critical that a balance between maintaining tolerance to the semi-allogenic fetus and upholding immune function for protection against infection is established to ensure a healthy pregnancy (1). A unique immunological crosstalk is established between mother and fetus which continues postpartum through breastfeeding. Important to this process of immune adaptation is the increase of innate immune cells at the maternal-fetal interface, specifically natural killer (NK) cells and macrophages, evident from the very beginning of pregnancy $(2,3)$. These macrophages and NK cells not only regulate local immune function but also directly promote migration and other functions of extravillous trophoblasts (EVT), support spiral artery remodeling and angiogenesis, and provide mediators that support fetal growth and development; all critical processes in placental and fetal development (4-6). Macrophages remain an important immune cell 
type to the maternal-fetal dyad post-partum as they exist in high numbers in breast milk and provide an element of protection against infection and inflammation to the nursing infant $(7,8)$.

Macrophages are found in all tissues where they play a role in maintaining tissue homeostasis and responding to the presence of infectious and non-infectious threat via the detection, ingestion and elimination of dead cells, foreign matter and other debris (9). They are a heterogenous population of immune cells displaying remarkable plasticity with their phenotype and function very much dependent on the local tissue microenvironment (6). Macrophages are classically divided into two groups; M1 macrophages (stimulated by interferon (IFN $\gamma$ ) or Toll-like receptor (TLR) ligands, such as lipopolysaccharide (LPS)) typically associated with proinflammatory responses and M2 macrophages (stimulated by interleukin (IL)-4/IL-13) typically associated with antiinflammatory responses (10). While this has emerged as an over-simplification of the spectrum of macrophage phenotypes linked to specific effector functions it provides a starting point for discussing the role of macrophages in pregnancy. As such, the balance of macrophage polarization at the maternal-fetal interface has emerged as vital in sustaining a healthy pregnancy. Throughout gestation the number and proportion of M1/M2 macrophages at the maternal-fetal interface is finely tuned with the initial polarization state skewed towards M1 during the window of implantation contributing to the inflammatory response that is important for successful implantation (11). As pregnancy progresses M2-like macrophages are more abundant in order to establish and maintain tolerance to the fetus as well as contribute to the normal development and functioning of the placenta $(5,12,13)$. Parturition has been characterized as an inflammatory process with macrophages being key to this process as demonstrated by increased numbers of M1 macrophages in the decidua of laboring tissue $(14,15)$. Failure to support the necessary immunological changes by macrophage maladaptation to or perturbations in the local tissue microenvironment, possibly due to alterations in the wider environment that the mother is being exposed to, is increasingly implicated in various pregnancy complications such as preeclampsia and preterm birth $(1,16)$.

This review will discuss the current understanding of the role of macrophages in the reproductive setting, namely the maternalfetal interface as well as in breast milk, and the environmental factors that can influence their function including infection, obesity, and pollution.

\section{MACROPHAGE POLARIZATION AND PLASTICITY}

The diverse roles of macrophages are governed by their incredible plasticity. In response to extrinsic factors derived from the tissue microenvironment, macrophages activate different intracellular pathways leading to specific polarization patterns. As noted above, macrophages are categorized broadly into classically
activated/M1 macrophages or alternatively activated/M2 macrophages and based on their response to differing stimuli M1 macrophages were suggested to preferentially elicit a Th1 type response and M2 a Th2 response (17-19). However, we now know that these classifications represent macrophages at either ends of a continuum and macrophage phenotype may be better described as a series of gradations within a large spectrum (20). Consequently, M2 macrophages have been further categorized into M2a, M2b, $\mathrm{M} 2 \mathrm{c}$, and M2d based on the molecules that lead to their activation as well as their gene expression profiles (21). The various groups of macrophages differ in their expression of cell surface markers, cytokine secretion and biological function which are summarized in Figure 1.

The activation of macrophages by LPS and Th1 cytokines (including IFN $\gamma$ and $\mathrm{TNF} \alpha$ ) results in M1 polarization with granulocyte-macrophage colony-stimulating factor (GM-CSF) also implicated as an important M1-inducer (22). These macrophages are characterized by surface marker expression that includes CD80, CD86, TLR4, and TLR2 and the release of cytokines and chemokines such as TNF $\alpha$, IL-1 $\beta$, CXCL9, and CXCL10. These soluble mediators drive further M1 polarization via positive feedback, yielding potent pro-inflammatory cells with critical microbicidal and tumoricidal functions (Figure 1) (22). M2 polarization on the other hand is induced by signals from anti-inflammatory cytokines such as IL-4 and IL-13 as well as macrophage colony-stimulating factor (M-CSF) (22). M2 macrophages express surface markers such as CD206, CD209, and CD163 and upregulate the production of cytokines and chemokines such as IL-10, transforming growth factor (TGF- $\beta$ ), CCL1, and vascular endothelial growth factor (VEGF; Figure 1). M2 macrophages play important roles in tissue repair, angiogenesis, and immunomodulation (22).

A growing body of evidence demonstrates specific metabolic processes as critical determinants of immune cell effector functions including macrophages. A multitude of metabolic processes have been implicated in pro- and anti-inflammatory macrophage activation. These processes include glycolysis, the Krebs cycle, oxidative phosphorylation (OXPHOS), amino acid metabolism and fatty acid metabolism (23). Under homeostatic conditions and in an anti-inflammatory environment, macrophages rely primarily on catabolic pathways such as glucose oxidation for their energy supply and function $(24,25)$. Upon activation via pattern recognition receptor (PRR; e.g. TLR) signals, macrophages engage in anabolic metabolism in order to maintain inflammatory function $(24,26)$. Thus in M1 macrophages, aerobic glycolysis is recognized as a crucial metabolic event with inhibition of glycolysis affecting proinflammatory functions such as phagocytosis and cytokine release $(27,28)$. A high proportion of glycolysis-derived carbon is shunted into the pentose phosphate pathway to produce biosynthetic precursors required for nucleotide synthesis (pentose sugars and ribose-5-phosphate), and nicotinamide adenine dinucleotide phosphate (NADPH) which is required for reductive biosynthesis reactions and as a substrate for NADPH oxidase (NOX2) to generate ROS as part of their anti-microbial response $(29,30)$. 


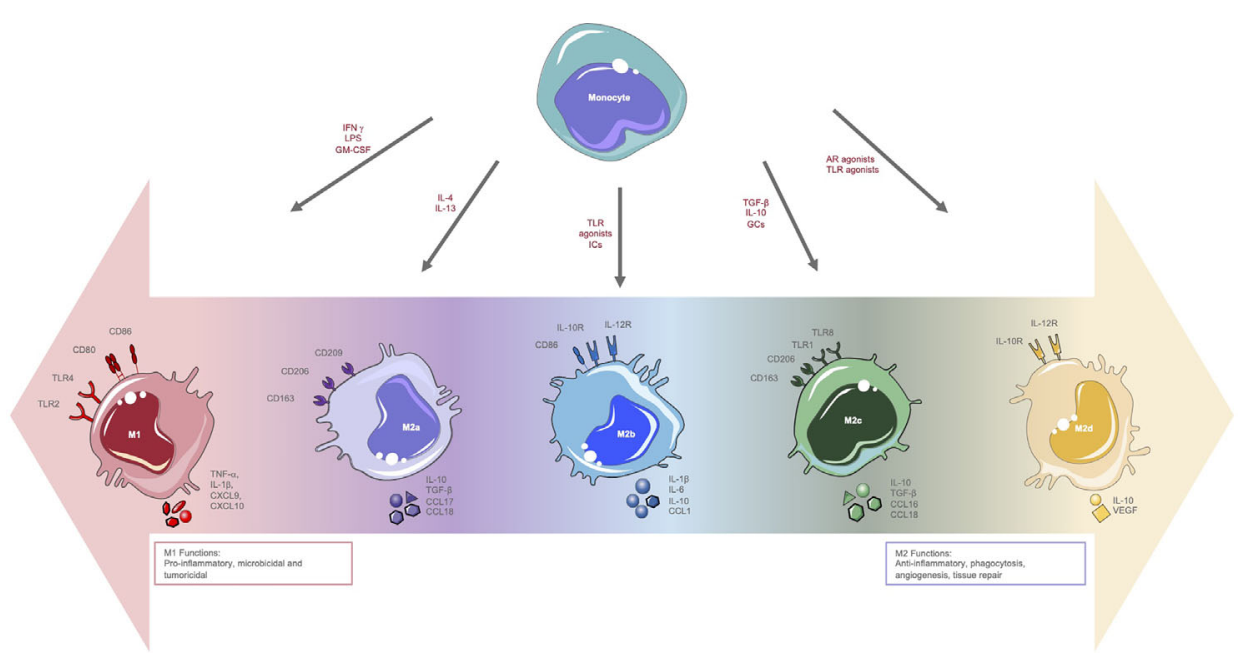

FIGURE 1 | Macrophage polarization. Overview of the polarization spectrum of macrophages highlighting stimuli, surface marker expression, cytokine and chemokine secretion and functions of $\mathrm{M} 1$ and $\mathrm{M} 2$ polarized macrophages. $\mathrm{AR}$, adenosine receptor; $\mathrm{CCL}$, chemokine (C-C motif) ligand; $\mathrm{CXCL}$, chemokine (C-X-C) ligand; IFN $\gamma$, interferon-gamma; GC, glucocorticoids; IC, immune complexes; LPS, lipopolysaccharide; MHC, major histocompatibility complex; TGFb, transforming growth factor-beta; TNF $\alpha$, tumour necrosis factor alpha; TLR, Toll-like receptor; iNOS, inducible nitric oxide synthase; VEGF, vascular endothelial growth factor.

The Krebs cycle has emerged as a central immunometabolic regulator of macrophages, at least in mice, with specific breakpoints in the cycle resulting in accumulation of the intermediates succinate and citrate during pro-inflammatory macrophage activation. These metabolites are involved in the regulation of inflammatory gene expression $(31,32)$. The metabolite itaconate, which is synthesized from the Krebs cycle intermediate cis-aconitate, is also an important immunomodulator in M1 activated macrophages. Itaconate is produced in large quantities in LPS activated macrophages where it regulates inflammation by inhibiting pro-inflammatory cytokine and ROS production (33). Itaconate additionally displays antimicrobial properties by inhibiting bacterial isocitrate lyase (34). Another Krebs cycle intermediate, $\alpha$-ketoglutarate, has been demonstrated as crucial for complete murine M2 macrophage activation via epigenetic alterations in M2-associated genes. These epigenetic alterations involve the demethylation of histone H3 K27 on the promoters of M2 marker genes thus enhancing their expression (35). However, while the Krebs cycle is implicated in both M1 and M2 polarization, it is intact in M2 cells with no breakpoints observed. M2 macrophage metabolism is also characterized by enhanced glucose oxidation via OXPHOS, with the antiinflammatory cytokine IL-10 reported to stimulate OXPHOS to oppose M1 polarization (36-38). Originally, fatty acid oxidation (FAO) was thought to be important in supporting OXPHOS in these anti-inflammatory macrophages, however, the importance of FAO in M2 polarization is under scrutiny as many studies based this conclusion on inhibition of carnitine palmitoyltransferase1A (facilitates long-chain fatty acid transport across the mitochondrial outer membrane) using etomoxir. However, high concentrations of etomoxir (exceeding $3 \mu \mathrm{M}$ ) have been demonstrated to disrupt free coenzyme A levels disrupting M2 polarization (39). The effect of FAO on murine macrophage polarization also has been studied using fatty acid transporter protein (FATP1) knockouts and overexpression models. FATP1 deficiency in macrophages induced a switch from FAO to glycolysis whereas overexpression inhibited pro-inflammatory macrophage responses supporting the hypothesis that FAO is important for antiinflammatory M2 polarization (40). However, despite this evidence linking murine M2 polarization to FAO, FAO was found to be dispensable for M2 polarization of human macrophages and the role of FAO in human M2 polarization awaits clarification (41). Differential metabolism of the amino acid arginine might also contribute to M1/M2 polarization. M1 macrophages favor the inducible nitric oxide synthase (iNOS) pathway in which arginine is converted to citrulline and nitric oxide (NO) enhancing cytotoxicity, whereas M2 macrophages utilize the arginase pathway which involves the hydrolysis of arginine into urea and ornithine which is important for cell proliferation and tissue repair (42). While there are many fascinating insights into the link between macrophage metabolism and function the vast majority of macrophage metabolism studies have been carried out using murine cells and availability of human data is limited. Thus, more effort to understand the effects of metabolism on macrophage polarization in humans is needed.

The polarization patterns of macrophages within the female reproductive system varies throughout the menstrual cycle and during pregnancy. These patterns are dependent on gestational age, must be finely tuned to ensure pregnancy success and are perturbed in adverse pregnancy outcomes. Here we will provide an overview of human macrophage populations within the non-pregnant uterus (uterine macrophages), pregnant uterus (decidual macrophages), placenta (placental macrophages or Hofbauer cells) and breast milk. While 
placental macrophages are of fetal origin all other populations are of maternal origin.

\section{Uterine Macrophages}

The uterine endometrium is an important site of mucosal immunity and must simultaneously maintain a hospitable environment for implantation while providing protection against pathogens. The physiological processes of the female reproductive system such as the menstrual cycle, implantation and the onset of labor all have been described as inflammatory events (43). Key to these inflammatory events are macrophages which are distributed throughout the uterine tissue and constitute about $10 \%$ of the leukocytes present in the human uterus and $10 \%$ of total uterine cells in the mouse $(44,45)$. These uterine macrophages have been demonstrated to display an M2like phenotype characterized by high secretion of antiinflammatory IL-10 and the typical M2 cell membrane markers CD163 and CD206 (46). This population of macrophages is likely regulated by the sex hormones estrogen and progesterone as inferred by the alterations in leukocyte populations which correspond to the menstrual cycle (Figure 2) $(47,48)$. Early murine studies revealed that ovariectomy, which prevents cyclical estrogen and progesterone production, leads to decreased macrophage numbers in the uterus within 6 days. Upon injection with estrogen and progesterone, macrophage numbers were restored highlighting a role for these hormones in macrophage regulation in the uterus (49). The macrophages in the uterine endometrium express the estrogen related receptor- $\beta$ indicating the possibility of estrogen-dependent regulation of these cells (50). However, uterine macrophages lack progesterone receptor expression implying indirect regulation via factors secreted by other progesterone-responsive endometrial cells (51). Progesterone and estrogen additionally stimulate uterine cells to produce MCSF and levels of this cytokine correlate to the presence of macrophages in the mouse uterus highlighting the role for sex steroids in controlling uterine macrophage numbers indirectly (52). The estrogen dominant follicular or proliferative phase of the menstrual cycle involves the proliferation and thickening of the endometrium. During the secretory or luteal phase of the menstrual cycle, in which progesterone dominates, decidualization involving morphological and functional changes of the endometrial stromal cells as well as spiral arteriole development to prepare for implantation begins (53). If implantation occurs, the decidualization reaction continues. However, in the absence of pregnancy, progesterone levels decrease resulting in an inflammatory cascade and the breakdown and loss of the functional layer of the endometrium in menses.

Despite the apparent M2 phenotype of uterine macrophages they secrete both anti-inflammatory (e.g., IL-10 and IL-1 receptor antagonist (IL-1RA)) and pro-inflammatory (e.g. TNF $\alpha$ and IL-1 $\beta$ ) cytokines and express variations of surface markers throughout the menstrual cycle (54). Macrophage numbers are low during the proliferative phase and they express the activation markers CD69 and CD71 and the adhesion marker CD54 suggesting their potential involvement

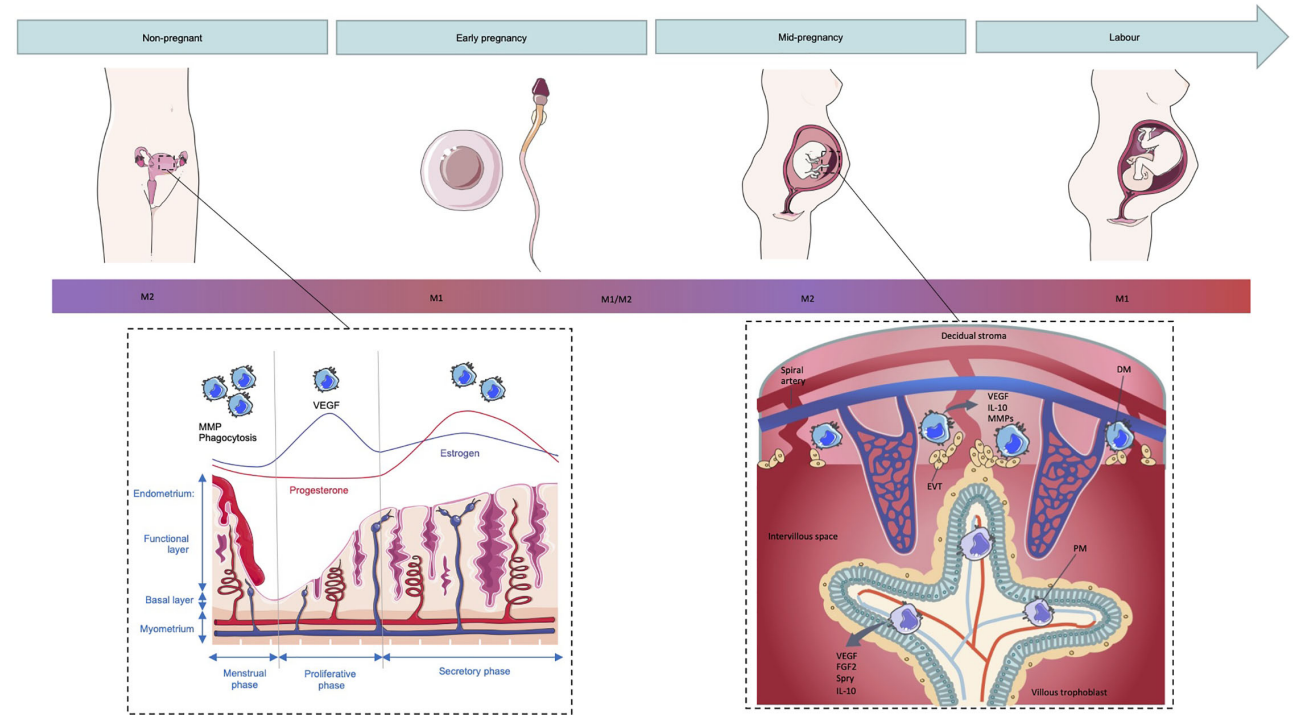

FIGURE 2 | Macrophage polarization in the non-pregnant and pregnant uterus. The number and function of macrophages in the non-pregnant uterus changes during the menstrual cycle with numbers peaking during menses where they play a role in the breakdown of the endometrial functional layer through secretion of MMPs as well as debris clearance through phagocytosis. Upon exposure to seminal fluid, the endometrium is thought to induce an inflammatory response resulting in the recruitment of macrophages that display an M1-like phenotype. As pregnancy proceeds and extravillous trophoblasts (EVTs) invade the decidual stroma, decidual macrophages (DMs) shift towards a mixed M1/M2 profile and eventually a predominantly M2 phenotype to prevent fetal rejection. Placental macrophages (PMs) additionally display an M2 phenotype and aid in regulation of angiogenesis in the feto-placental vasculature through secretion of VEGF and fibroblast growth factor (FGF)2. Term labor is associated with an increased number of M1 macrophages and inflammatory cytokines in the decidua and it is this inflammatory environment which is thought to induce labor. 
in the proliferation and regeneration of the functional endometrium (55). An influx of macrophages occurs in the secretory phase of the menstrual cycle where they are thought to be important in the preparation of the endometrium for implantation. Leukemia inhibitory factor (LIF) is a key molecule involved in implantation contributing through, for example, chemoattraction of macrophages. This role of LIF is best demonstrated in mouse models wherein LIF-knockout mice have a more than $50 \%$ reduction in macrophages in uteri that experience implantation failure (56).

The uterine macrophage population peaks during the menses phase following progesterone withdrawal (57). The decrease in progesterone levels as well as the release of paracrine factors from various cells of the endometrium results in the upregulation of matrix metalloproteinases (MMPs). These proteolytic proteinases are key to the breakdown of the endometrium during menstruation (58). Macrophages express various forms of these MMPs and additionally secrete various molecules involved in their regulation such as IL-17 which has been shown to upregulate MMP expression (59-61). Immunolocalization techniques have revealed that MMP-9 colocalizes with various leukocytes including macrophages immediately prior to and during menstruation suggesting that these immune cells are the major MMP-9 source in the menstrual tissue (61). MMP-12 is also secreted by uterine macrophages and is upregulated during menstruation highlighting the role of macrophage-derived MMPs in the tissue degradation associated with menstruation $(62,63)$. The endometrium resembles a "wound" during menstruation and it is critical that the woundhealing process maintains reproductive function (64). Inflammation is key to wound healing with macrophages having a pivotal role through removal of dead cells (64) and the remodeling of tissue (65). Endometrial cells shed during menstruation undergo apoptosis and are phagocytosed by macrophages (66). Subsequent vascular remodeling following progesterone withdrawal results in vasoconstriction and a hypoxic environment that creates proangiogenic macrophages and stimulates the release of VEGF by macrophages and stromal cells $(67,68)$.

Macrophages are therefore important for the normal functioning of the uterus throughout the menstrual cycle. Consequently, dysregulation of their activity seems to have a significant role in abnormalities and pathologies of the uterus including endometriosis and endometrial cancer (66). Endometriosis is a common condition affecting many menstruating women. It is characterized by hormone-dependent growth of vascularized endometrial tissue outside of the uterus resulting in pelvic pain and infertility. Macrophages are abundant in endometrial lesions found outside of the uterus (primarily in the peritoneum) and are implicated in endometriosis $(69,70)$. Macrophages within the peritoneum demonstrate increased secretion of pro-inflammatory cytokines (IL-1 $\beta$, IL-6, and $\mathrm{TNF} \alpha$ ) and angiogenic factors (VEGF) contributing to a microenvironment that favors the implantation of endometrial cells outside of the uterus to establish and maintain endometriosis (71). The growth of endometrial lesions is likely enhanced by the presence of macrophages as demonstrated by the increased proliferation and invasiveness of endometrial stromal cells when co-cultured with macrophages (72). As well as endometrial lesionassociated macrophages in the peritoneum, macrophages were also increased in the endometrium of women with endometriosis during the proliferative phase of the menstrual cycle however alterations in their functions are yet to be identified (66). Elevated macrophage numbers in the endometrium of women with endometriosis may be due to the increased levels of macrophage migration inhibitory factor (MIF) and monocyte/macrophage activating chemoattractant protein (MCP-1/CCL2) that simultaneously limit macrophage migration from and recruitment of macrophages into the endometrium, respectively $(73,74)$. It is not clear whether these alterations in macrophages and other immune cell types implicated in endometriosis are cause or effect (75) but clarification of mechanisms mediating macrophage maladaptation could be critical in the development of treatment for endometriosis.

\section{Decidual Macrophages}

As mentioned above, fluctuation of macrophage number and function in the endometrium is a physiological feature of the normal menstrual cycle in non-pregnant women (76). When pregnancy occurs there is an increase in the number of macrophages so that they comprise $20 \%$ to $30 \%$ of decidual leukocytes (77). During the peri-implantation period in mice, when the uterus is exposed to seminal fluid, there is an increase in M1-skewed macrophages (11) recruited by chemokines secreted by decidual stromal cells (78). The extent to which seminal fluid impacts the human endometrial environment is not well understood, however a similar inflammatory response is observed in the human cervix upon exposure to seminal fluid which results in the recruitment of leukocytes including macrophages, accompanied by inflammatory cytokines and chemokines such as IL-6 and IL-8 (CXCL8) (79). These immune changes are thought to facilitate preparation of the female reproductive tissue for pregnancy through clearance of debris and pathogens and sperm selection (80). Despite the primary site of semen deposition in the human female reproductive tract being the cervix, in vitro studies demonstrate that these immune changes probably extend to the uterus as seminal plasma was able to induce expression of proinflammatory cytokines in primary endometrial epithelial cells from fertile woman (81).

Although this initial inflammatory, pro-M1 period is key in the preparation for pregnancy, a shift towards a more immune tolerant environment must occur for pregnancy to continue (6). As EVTs begin to invade the uterine stroma, a mixed profile of M1/M2 macrophages is established (11). A shift towards a predominantly M2 phenotype then occurs in order to prevent fetal rejection (Figure 2) (6). However, the diverse phenotypes of decidual macrophages in the first and second trimester differ from conventional M1/M2 cells. Early murine studies demonstrated that macrophages, identified by expression of $\mathrm{Fc} \gamma$ receptor expression, isolated from the pregnant uterus were immunosuppressive as they were able to inhibit the 
inflammatory response of spleen cells to polyclonal mitogen phytohemagglutinin (PHA) suggesting that these macrophages may contribute to the immunoregulatory environment at the maternal-fetal interface (82).

Two distinct subsets of first trimester decidual macrophages classified by the level of expression of CD11c have been described (83). Gene expression analysis using RNA microarray revealed that CD11c hi macrophages express genes involved in inflammation and lipid metabolism such as OLR1 (oxidized low-density lipoprotein) and LPL (lipoprotein lipase). This subset was additionally much better at antigen processing and may therefore be the major antigen presenting population in the decidua. On the other hand, CD11 $c^{\text {lo }}$ macrophages upregulate expression of genes associated with extracellular matrix formation, muscle regulation, and tissue growth such as DMD (dystrophin), an important gene in muscle cell viability, and IGF1 (insulin-like growth factor 1), a gene important for the development and functional maturation of skeletal tissues and reproductive organs (83). However, both of these decidual macrophage subsets secrete pro- and anti-inflammatory cytokines and might contribute to the inflammatory balance during the first trimester that maintains immune homeostasis without compromising defense against invading pathogens at the maternal-fetal interface (83). In contrast, gene expression profiling and phenotyping by surface marker expression of term decidual macrophages demonstrates that they most closely resemble M2 skewed cells $(12,15,84)$. This phenotype is important for immunomodulatory functions and tissue remodeling (12). These term decidual macrophages are the major source of the immunosuppressive cytokine IL-10 in the decidua and display low expression of CD80 and CD86 (costimulatory molecules necessary for antigen presentation and $\mathrm{T}$ cell activation) thus confirming their immunomodulatory role (85). As well as IL-10, there are many other factors at the maternal-fetal interface that are responsible for modulating this phenotype. For example, trophoblast-derived M-CSF along with IL-10 have been demonstrated to induce this M2 regulatory phenotype in maternal monocytes (86). Soluble human leukocyte antigen G5 (sHLAG5), a soluble isoform of human leukocyte antigen, has additionally been implicated as an important soluble factor responsible for macrophage polarization during pregnancy. sHLAG5 is able to promote differentiation of macrophages to an immunomodulatory phenotype with reduced expression of CD86 and increased CD163 expression (87). These macrophages additionally displayed increased phagocytic ability as well as greater expression of indoleamine 2,3-dioxygenase [a marker of decidual macrophages (85)] and secretion of IL- 6 which prevented proliferation of and IFN- $\gamma$ production by $\mathrm{T}$ cells.

Decidual macrophages have been reported to be involved in various stages of placental development. They contribute to decidual invasion of EVT from placental villi and uterine spiral artery remodeling that support the nutritional and oxygen demands of the growing fetus. As with endometrial remodeling in the menstrual cycle the production of MMPs, specifically MMP-7 and -9, is critical as these degrade the extracellular matrix enhancing EVT invasion (88). Additionally, the secretion of M2-associated factors such as IL-33 and Wnt-5a by decidual macrophages may enhance proximal cell column proliferation and could be important for EVT development (89). Macrophages also localize in the immediate vicinity of spiral arteries even before EVTs are present highlighting their role in early vascular remodeling (88).

Apoptosis is central to appropriate development of the decidua (90), for example, trophoblast cells lost via apoptosis are replaced with a younger population (91), and macrophages engulf these apoptotic cells preventing the release of their potentially pro-inflammatory and pro-immunogenic intracellular contents that might be lethal for the fetus (90). Thus, appropriate removal of apoptotic cells by macrophages and potentially the production of anti-inflammatory mediators such IL-10 and TGF- $\beta$ in response to apoptotic cells (92) is important for maintaining tissue homeostasis at the maternalfetal interface.

While an M2-like decidual macrophage phenotype dominates for much of pregnancy, labor at term is associated with an increased number of M1 macrophages when compared with term in the absence of labor suggesting a role for proinflammatory macrophages in the induction of term labor (15). Additionally, parturition is associated not only with the infiltration of macrophages but also increased mRNA expression of the pro-inflammatory cytokines IL1B and IL6 in laboring tissue (93). However, an earlier study identified only marginal differences in macrophage activation status between spontaneous vaginal delivery compared with caesarean section questioning the involvement of decidual macrophage activation in parturition (84).

\section{Placental Macrophages}

Placental macrophages, also known as Hofbauer cells, are fetal macrophages found within the chorionic villi. They appear as early as the 18th day of gestation and are round, highly vacuolated cells (94). As placental macrophages are observed before the fetal circulation is established, it is suggested that they are derived from mesenchymal cells in the villous stroma from early stages of gestation (95-97). A recent study additionally concluded that first trimester placental macrophages were derived from primitive hematopoiesis as they are transcriptionally similar to yolk sac derived macrophages but not embryonic monocytes (98). Other studies have suggested that upon development of the fetal circulation, placental macrophages are recruited from fetal monocytes in later stages of pregnancy as transitional forms of monocytes and placental macrophages are observed (99-101). The pool of placental macrophages is thought to be sustained through recruitment of monocytes by factors such as MCP-1 produced by villous fibroblasts (102). It is additionally debated whether placental macrophages are able to self-renew with some studies demonstrating mitotic activity (103) while others did not (104). Placental macrophages also have been shown to display an M2like phenotype. M1-associated genes such as TLR9, IL1B, IL12RB2, and $C D 48$ were silenced by hypermethylation whereas pro-M2 genes including CCL2, CCL13, CCL14, and CD209 were 
hypomethylated (105). Flow cytometry confirms the presence of the M2 cell surface markers CD209 and CD206 on placental macrophages and supernatants from these cells have high concentrations of immunosuppressive cytokines such as IL-10 and TGF- $\beta(106,107)$. This M2 phenotype aids in the prevention of fetal rejection and allows for fetal growth (107) and is dictated by the local microenvironment. For example, M1 polarized monocyte-derived macrophages favor the M2 phenotype upon co-culture with placental mesenchymal stem cells isolated from the chorionic villi (108).

The phenotype and function of placental macrophages remains poorly understood and has recently been debated due to the finding that a population of maternal derived macrophages is present in placental digests that have likely been unaccounted for in previous studies (98). Despite this, a number of studies support a key role for them in angiogenesis, vasculogenesis, and placental mesenchyme development $(94,109,110)$ which remains true even with the removal of this contaminating population of maternal macrophages (98). The placenta is a highly vascularized organ and placental macrophage secretion of VEGF and fibroblast growth factors (FGFs) such as FGF2 underscores their likely role in the regulation of angiogenesis in the feto-placental vasculature $(109,111)$. Additionally, placental macrophages express Sprouty (Spry) proteins which are involved in regulating branching morphogenesis and attracting fibroblasts to support this process (102). Although characterized as M2-like, placental macrophages can mount a pro-inflammatory response upon activation via TLRs $(98,112)$. TLRs are a group of transmembrane proteins that function as PRRs, recognizing pattern-associated molecular patterns (PAMPs) and danger-associated molecular patterns (DAMPs) (113). Activation of term placental macrophages via TLR4 (with LPS) or TLR3 (with polyinosinic-polycytidylic acid (poly I:C)) increased IL- 6 and IL- 8 secretion suggesting that placental macrophages have an important role in host defense within the placenta and the triggering of local inflammation (112). Placental macrophage anti-viral responses have been studied further using $5^{\prime}$ triphosphate double-stranded RNA (5'ppp-dsRNA) which is a synthetic ligand for the retinoic acid-inducible protein I (RIG-I) (114), another type of PRR. There are gestational differences in the capacity of placental macrophages to respond to 5'pppdsRNA. Early/mid gestation placental macrophages quickly adopted classically activated phenotypes with the production of some inflammatory cytokines whereas term macrophages remained outwardly inactivated despite the transcriptional upregulation of the antiviral genes MX1 and Viperin (114). These results suggest that placental macrophage response to viral stimulation may be temporally regulated across gestation. First trimester placental macrophages additionally demonstrate microbicidal activity as they display phagocytic capacity and ROS production (98).

\section{Breast Milk Macrophages}

Macrophages continue to have an important role even after the baby is born via the breast milk. Breast milk is composed of many immunological factors which facilitate immune development of the neonate (115). Macrophages are present in breast milk in large numbers comprising up to $80 \%$ of total cells in early human milk with numbers per milliliter of milk declining with milk maturation (116). These cells are thought to be derived from maternal peripheral blood monocytes which extravasate and migrate to the mammary gland and enter the breast milk through the epithelium. Upon arrival, breast milk macrophages demonstrate great phagocytic activity without prompting a significant, uncontrolled immune reaction that would result in inflammation and tissue damage (117).

Although monocytes are thought to be the precursors of breast milk macrophages, these two populations have distinct phenotypes. Breast milk macrophages are larger, contain numerous cytoplasmic inclusions and display increased expression of molecules involved in $\mathrm{T}$ cell stimulation, including HLA-DR, CD86, and CD40 (116). The glycoprotein CD83, a molecule expressed by mature dendritic cells (DCs) and in activated cells of other lineages such as neutrophils (118), is expressed by breast milk macrophages but not monocytes (116). These results suggest that breast milk macrophages are committed to DC differentiation. This is also supported by their spontaneous production of GM-CSF, the most potent monocyte-derived DC differentiation factor. Indeed, upon exposure to IL- 4 breast milk macrophages can differentiate into DCs able to stimulate $\mathrm{T}$ cells and potentially mediate $\mathrm{T}$ cell dependent immune responses (116). Breast milk macrophages also secrete the multifunctional protein osteopontin which activates Th1 cells highlighting the role for these macrophages in $\mathrm{T}$ cell modulation (119). A Th1 gastrointestinal environment in the infant has been implicated in the prevention of allergies however clear evidence is limited due to environmental influences on individual levels of any mediators measured in breast milk (119). Breast milk macrophages can survive in the neonatal murine gut for several hours with some mucosal uptake suggesting a direct contribution of breast milk macrophages to gastrointestinal immune response in the offspring (120). However, the function and transfer of breast milk macrophages in human infants remains poorly understood.

Breast milk macrophages are also suggested to have a host defense role. An increase in breast milk macrophage numbers beyond what is considered normal at the different lactation stages occurs with infection in both the mother and infant $(121,122)$. However, as well as this protective role, breast milk macrophages might contribute to mother to child transmission of pathogens (123). For example, TLR10 is especially overexpressed on breast milk macrophages from women infected with HIV-1 compared with uninfected women. TLR10 contributes to HIV-1 infection and replication in breast milk macrophages through interaction with the HIV-1-specific structural protein gp41 leading to the production of IL-8 (124).

\section{Environmental Factors Implicated in Adverse Obstetric Outcomes}

The central role of macrophages is to respond to the local tissue environment to maintain and restore tissue homeostasis 
including mounting an inflammatory response to pathogenic and non-pathogenic insult. Consequently, macrophages are uniquely positioned to respond to maternal environmental pressures with infection and obesity among the most studied but with increasing interest in other factors such as air pollution. The effects of environmental influences on macrophage phenotype and function at the maternal-fetal interface and resulting adverse outcomes are summarized in Figure 3.

\section{Infection}

Infection is included here as the best studied environmental influence to provide a comparison to the other environments of interest rather than an extensive review. The immune response during pregnancy is finely controlled to allow close contact between maternal and fetal cells. However, maternal systemic infections as well as ascending infections from the vagina can result in placental dysfunction and thereby adverse pregnancy outcomes (Figure 3). Viruses and bacteria can reach the decidua and placenta through hematogenous transmission or by ascending from the lower reproductive tract (125). Infection by the family of TORCH organisms which include Toxoplasma, Others (syphilis, varicella-zoster, parvovirus B19), Rubella, Cytomegalovirus (CMV), and Herpes as well as Hepatitis E virus (HEV-1) and Zika virus (ZIKV) during pregnancy can result in severe maternal and/or fetal morbidity (126). Decidual and placental macrophages have been proposed as a line of defense against these pathogens however progressive research has demonstrated that these macrophages rather harbor live pathogens serving as a reservoir for fetal infection $(127,128)$. These invading pathogens manipulate the macrophages resulting in perturbed function. For example, infection of placental macrophages by ZIKV results in cell proliferation and hyperplasia of these cells (129). ZIKV infection also increased secretion of pro-inflammatory cytokines, such as IFN $\alpha$ and IL-6, and chemokines such as MCP-1, implicated in monocyte infiltration, and IP-10, involved in effector T cell recruitment

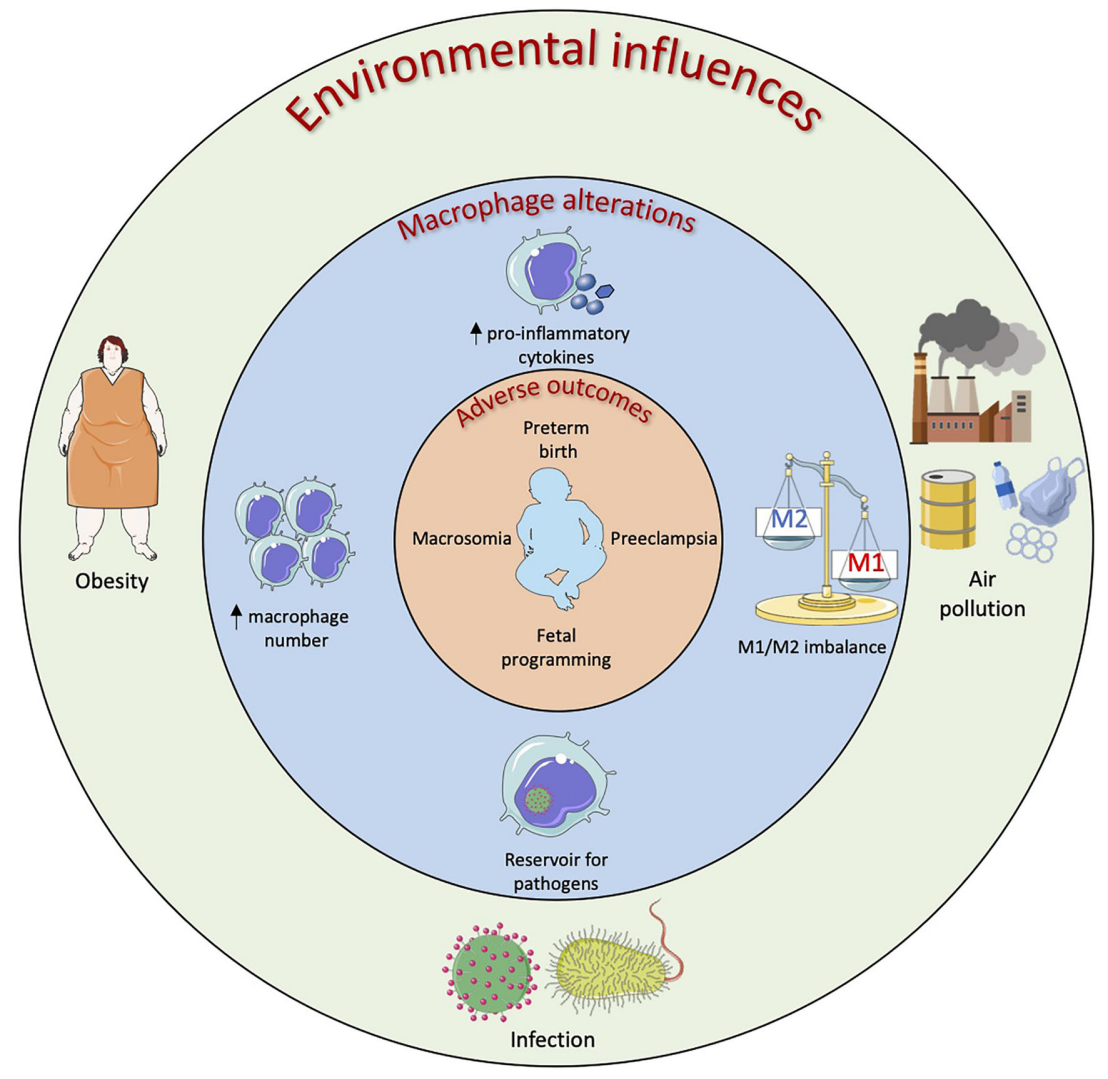

FIGURE 3 | Environmental influences on macrophages in the female reproductive system resulting in adverse obstetric outcomes. Maternal obesity, infection and air pollution have all been linked to adverse obstetric outcomes and this could be linked to macrophage alterations at the maternal-fetal interface. Obese mothers have demonstrated increased numbers of placental macrophages along with increased levels of pro-inflammatory cytokines. This placental inflammation has been linked to preeclampsia, preterm birth and fetal programming of organ function. In utero infection by bacteria and viruses can result in neural defects, preterm and stillbirth. Placental and decidual macrophages have been shown to act as reservoirs for these pathogens as well as upregulate their pro-inflammatory cytokine production resulting in an imbalance of $\mathrm{M} 1 / \mathrm{M} 2$ macrophages at the maternal-fetal interface. Air pollutants such as black carbon and chemicals found in plastics that are inhaled as well as ingested can cross the placental barrier and be phagocytosed by macrophages. The effects of air pollution on placental/decidual macrophage function are yet to be fully elucidated however certain pollutants have been shown to increase pro-inflammatory cytokine production as well as increase prostaglandin production which could lead to preterm birth. 
(128). The putative migratory abilities of these infected placental macrophages might facilitate the spread of the virus to the fetal brain resulting in neural abnormalities and microcephaly (130).

Aberrant macrophage activation also occurs with Toxoplasma gondii infection during pregnancy, especially if this occurs during the first trimester, and can lead to neural defects as well as stillbirth, miscarriage and preterm labor (131). A number of studies have demonstrated aberrant decidual macrophage activation upon infection with T. gondii. Expression of M1associated molecules, such as CD80 and CD86, was upregulated and M2 functional molecule expression was down-regulated in infected decidua $(131,132)$. T. gondii infection also increased pro-inflammatory cytokine secretion from decidual macrophages which have been shown to induce trophoblast apoptosis $(131,133)$. Altered balance of M1 versus M2 decidual macrophages might contribute to T. gondii-mediated adverse obstetric outcomes by dysregulating immune tolerance.

Placental macrophages can however provide some protection against certain infections. For example, they have been found to limit HIV-1 replication and possibly contribute to reduced mother to child transmission despite the expression of HIV-1 co-receptors such as CD4 and DC-SIGN on their surface (107). This limited replication is thought to be due to the increased production of immunoregulatory cytokines such as IL-10 by these placental macrophages as IL-10 has been shown to inhibit HIV-1 replication (107).

Therefore, macrophages at the maternal-fetal interface are a double-edged sword during infection as polarization towards an M1 microbicidal phenotype will result in compromised tolerance and threat to fetal health however an anti-inflammatory M2 phenotype compromises maternal and fetal protection from pathogens.

\section{Obesity}

Obesity in women of child-bearing age is increasing worldwide. The 2019 National Maternity and Perinatal Audit Clinical Report reports that more than half $(50.4 \%)$ of UK women were overweight or obese at the time of initial antenatal booking appointment and an estimated obesity prevalence of $31.8 \%$ in women aged 20-39 years was recorded in the United States in $2012(134,135)$. Obesity has been associated with infertility as well as a number of obstetric complications such as spontaneous miscarriage, preeclampsia and macrosomia (Figure 3) (134). The mechanisms underpinning this are not completely understood but as obesity demonstrates characteristics of a low-grade inflammatory state (136), an altered immune balance likely contributes. Little data is available on the role uterine macrophages play in infertility in obese woman however a study on women with polycystic ovary syndrome (which is associated with infertility) revealed that obesity induces an inflammatory environment with increased numbers of macrophages and TNF $\alpha$ signaling in the endometrium of these women (137). This inflammatory environment could contribute to fertility failures in these women. Additionally, obesity is a risk factor for the gynecological disorder known as adenomyosis which is characterized by invasion of endometrial glands and stroma within the uterine myometrium $(138,139)$. Women with adenomyosis have reduced IVF implantation rates and it has been demonstrated that there is an increased density of macrophages and NK cells in these women suggesting successful implantation in these women may be hindered through an immunological mechanism (140). Placental macrophages are emerging as having a role in this with increased numbers in placentas from obese compared with normal weight women and an accompanying augmentation of the pro-inflammatory cytokines TNF $\alpha$, IL-1, and IL-6 (141). However, not all studies report an increase in placental macrophages with maternal obesity although greater expression of pro-inflammatory cytokines in placentas of obese women is emerging as a consistent finding (142). Placental macrophages therefore seem to be contributing to the inflammatory environment observed in chronic villitis associated with maternal obesity (143). Placental macrophages express PRRs such as TLR4 and can bind saturated fatty acids to induce production of potent pro-inflammatory mediators such as TNF $\alpha$, IL-6, and IL-8 $(144,145)$. An in vitro model of obesity using high levels of glucose, insulin and palmitic acid (saturated lipid) in culture additionally demonstrated that palmitate alone was enough to cause NLRP3 inflammasome activation, resulting in the release of IL-1 $\beta$, as well as induce placental macrophage apoptosis (146). This placental inflammation might have negative impacts on the development of the fetus, including the brain, resulting in long term alteration in neural function (147).

The effects of obesity on decidual macrophage populations have also been studied. Macrophage populations in the decidua parietalis of obese women show fewer M1 macrophages but no change in M2 macrophages compared with healthy controls (148). This decrease in M1 macrophages in the decidua parietalis might be a compensatory mechanism for the heightened inflammatory state observed in obesity. While only term placentas from uncomplicated pregnancies were included in this study, it was suggested that failure of this compensatory mechanism could lead to adverse pregnancy outcomes associated with obesity (148).

Obesity has been considered a risk factor for preeclampsia, a condition characterized by new onset hypertension and proteinuria (149). Preeclampsia is associated with deficient spiral artery remodeling and is linked to altered numbers of placental immune and trophoblast cells (149). Many mechanisms linking the two conditions have been proposed including that insulin resistance and hyperinsulinemia (commonly observed in obesity) precede the clinical manifestation of preeclampsia (150). Additionally, increased insulin levels in pregnant rodents led to raised blood pressure (151). Metabolic alterations associated with obesity including hyperinsulinemia, hyperleptinemia and hyperlipidemia all affect placental function and perfusion (152). Increased levels of lowdensity lipoproteins (LDL) and triglycerides have been observed in women with preeclampsia and LDLs have been reported to reduce trophoblast migration (153). Increased numbers of decidual macrophages from patients with preeclampsia that 
were localized to the spiral arteries whereby trophoblast invasion was reduced also has been demonstrated (154). While apparently paradoxical, this increase in placental macrophages might accompany the increased apoptosis of placental trophoblasts implicated in preeclampsia pathogenesis (155). This likely reflects increased sensitivity of EVTs to Fas-mediated apoptosis (156) with decidual macrophages in preeclamptic placentas displaying increased Fas-ligand expression potentiating their ability to induce Fas-mediated apoptosis of the Fas-expressing trophoblasts and limiting trophoblast invasion (155). Restricted trophoblast invasion leads to decreased spiral artery remodeling and reduced uteroplacental blood flow. $\mathrm{TNF} \alpha$ has a key role in this increased apoptosis of trophoblast implicating M1-like macrophages (157). Local enhanced levels of GM-CSF, a potent inducer of M1 macrophages (see Figure 1), occurs in the preeclamptic placenta and might underpin changes in macrophage phenotype and function (158). However, the increase in pro-inflammatory cytokines will stimulate decidual cells to upregulate factors, such as M-CSF, that induce M2 polarization for increased phagocytosis of the apoptotic trophoblasts (159).

Studies on the effects of maternal obesity on breast milk macrophage phenotype and function are limited. Two recent $e x$ vivo studies revealed that breast milk macrophages from mothers with high BMI displayed reduced phagocytic ability as well as reduced ROS production upon exposure to zymosan particles $(160,161)$. These results suggest that breast milk macrophages from obese mothers might be less efficient at responding to infection.

\section{Air Pollution}

Tobacco smoke exposure is the best studied maternal inhaled exposure and the detrimental effects of tobacco smoking on pregnancy outcomes such as miscarriage, stillbirth and preterm birth are well recognized (162). Many molecules in tobacco cigarettes can cross the placental barrier and affect placental function and fetal development but the specific causal mechanisms are not completely understood (163). Term placental macrophages become dysfunctional upon in vitro exposure to cigarette smoke extract (164). Phagocytosis is compromised and increased release of TNF $\alpha$ and IL-33 but decreased IL-10 potentially perturbs the immune tolerance ecosystem within the placenta leading to adverse pregnancy outcomes. Increasing epidemiological and experimental evidence highlight an association between other air pollution exposures during fetal development and similar adverse obstetric outcomes including low birth weight, preterm birth and preeclampsia as well as long term-term complications for the offspring $(165,166)$. While numerous studies have described these associations, little is known about the mechanisms underpinning these adverse outcomes. Both indirect (such as respiratory and intrauterine inflammation) and direct (such as particle translocation) processes probably contribute. Black carbon, as found in particulate matter (PM), has been observed in the human placenta where it seems to localize to and be phagocytosed by placental macrophages (167, 168). PM negatively affects placental trophoblast cells with endocytosis- mediated accumulation of PM associated with increased IL-6 production and decreased cell growth linked to decreased human chorionic gonadotropin (hCG $\beta$ ) (169). Other phenotypic responses of trophoblast exposed to PM related to molecular transport, cell survival and inflammation were reminiscent of those described in preeclampsia and intrauterine growth restriction but effects of PM on human placental macrophages are unknown. Mouse placental macrophage exposure to PM significantly increased gene expression of inflammatory markers such as $I L-1 B$ and oxidative stress markers such as heme oxygenase 1 (170) further highlight the need to study the effects of PM on human placental macrophages.

Studies on the effects of other pollutants on reproductive tract macrophages are emerging. Diethylhexyl phthalate (DEHP) is a pollutant that can be found in dust and can be inhaled. DEHP is commonly used in the production of polyvinyl chloride (PVC) products such as pipes, medical devices and automotive parts. If DEHP is not covalently bonded to the PVC it can be released into the environment. The active metabolite of DEHP is mono-2ethylhexyl phthalate (MEHP) and exposure to this metabolite during the prenatal period is associated with increased risk of preterm birth (171). MEHP has been found in maternal serum, placental tissue, fetal cord serum and amniotic fluid indicating that the metabolites of DEHP are transferable to the fetus from maternal blood (172). Exposure of placental macrophages to MEHP resulted in significantly increased prostaglandin E2 ( $\mathrm{PGE}_{2}$; a labor inducer) levels perhaps providing a link between DEHP exposure, placental macrophages and preterm birth (173).

Environmental pollutants can additionally be transferred from mother to infant postnatally through the breast milk (174). One example of these toxic compounds is the metal barium which is present in natural sources such as rocks and contaminate drinking water or can be released into the environment through industry (175). Barium chloride nanoparticles have toxic effects on breast milk phagocytes including reduced cell viability and intracellular calcium release which is important in promoting cell activity (175). Exposure to barium chloride also increased apoptosis in breast milk phagocytes suggesting that reduced numbers might reach the infant and therefore negatively affect their immune development.

While data on the effects of air and other pollutants, other than environmental tobacco smoke, on different reproductionassociated macrophages is nascent there is clearly a need to investigate these interactions given the long-term health detriments for the fetus of exposures during pregnancy.

\section{DISCUSSION}

Macrophages are significant contributors to immune function and homeostasis at the maternal-fetal interface. Compelling evidence suggests that these cells are involved in various stages of reproduction including implantation, placentation, pregnancy maintenance, parturition and in the development of the neonatal immune system through breastfeeding. The ability of macrophages to perform this plethora of functions is due to their high plasticity, with their phenotype governed by the local 
tissue microenvironmental milieu. Precise regulation of macrophage polarization is necessary for successful pregnancy. Alterations in macrophage polarization due to environmental influences are proposed in pregnancy complications however the mechanisms involved have not been elucidated fully.

Macrophage plasticity along with their significant role in directing pregnancy outcomes offers potential therapeutic targets in pregnancy complications. Modulating macrophage phenotypes through immunotherapy could prevent adverse pregnancy outcomes. The modulation of macrophage phenotype using epigenetic modifiers has been carried out with success in inflammatory disease models such as acute lung injury in mice (176). Epigenetic modulators could have therapeutic potential in ameliorating adverse obstetric outcomes, but one has to question what affect these epigenetic alterations might have on the baby. Recent data has provided insight into the contribution of cellular metabolic pathways such as glycolysis and oxidative phosphorylation to macrophage phenotype plasticity (23). Therefore, there is scope to therapeutically target these events too as already postulated for autoimmune diseases and cancer (177179). For example, dimethyl fumarate (DMF), a cell permeable derivative of fumarate, targets and inactivates the glycolytic enzyme glyceraldehyde 3-phosphate dehydrogenase (GAPDH) downregulating glycolysis and preventing activation of macrophages leading to a balance of inflammatory and regulatory cells (178). DMF is used to treat relapsing multiple sclerosis by inhibiting pro-inflammatory pathways and offers potential for treating the pro-inflammatory profile of many adverse pregnancy outcomes. However, again application in the reproductive setting might be challenging and we lack fundamental information about the relative contribution of different cellular metabolic processes to macrophage function at different sites and at different stages of pregnancy as well as in breast milk postnatally. Effort needs to be made to elucidate the signaling pathways and specific mechanisms controlling macrophage polarization in reproductive tissues for fundamental insight and translation for the development of

\section{REFERENCES}

1. Girardi G, Yarilin D, Thurman JM, Holers VM, Salmon JE. Complement activation induces dysregulation of angiogenic factors and causes fetal rejection and growth restriction. J Exp Med (2006) 203:2165-75. doi: $10.1084 /$ jem.20061022

2. Jiang X, Du MR, Li M, Wang H. Three macrophage subsets are identified in the uterus during early human pregnancy. Cell Mol Immunol (2018) 15:1027-37. doi: 10.1038/s41423-018-0008-0

3. King A, Balendran N, Wooding P, Carter NP, Loke YW. CD3- Leukocytes present in the human uterus during early placentation: phenotypic and morphologic characterization of the CD56++ population. Dev Immunol (1991) 1:169. doi: 10.1155/1991/83493

4. Lash GE, Schiessl B, Kirkley M, Innes BA, Cooper A, Searle RF, et al. Expression of angiogenic growth factors by uterine natural killer cells during early pregnancy. J Leukoc Biol (2006) 80:572-80. doi: 10.1189/jlb.0406250

5. Lash GE, Pitman H, Morgan HL, Innes BA, Agwu CN, Bulmer JN. Decidual macrophages: key regulators of vascular remodeling in human pregnancy. J Leukoc Biol (2016) 100:315-25. doi: 10.1189/jlb.1A0815-351R

6. Ning F, Liu H, Lash GE. The role of decidual macrophages during normal and pathological pregnancy. Am J Reprod Immunol (2016) 75:298-309. doi: $10.1111 /$ aji.12477 therapeutics to counter adverse obstetric and longer-term health outcomes.

A potentially less hazardous approach to modifying reproductive macrophage behavior might be through lifestyle modification and nutraceutical approaches to achieve local microenvironmental changes that translate as change to macrophage function. Perhaps therefore the most effective way to avoid adverse obstetric outcomes due to environmental influences would be to educate women as to the effects of these factors and highlight the importance of a healthy lifestyle to minimize obesity, exposure to infection and environmental pollutants prior to conception and during pregnancy and breastfeeding.

\section{AUTHOR CONTRIBUTIONS}

MC and CT conceived and designed the review. MC wrote the first draft of the manuscript. AR, NJ and CT wrote sections of the manuscript. MN provided clinical oversight. JG and NJ provided oversight of immunometabolism. All authors contributed to the article and approved the submitted version.

\section{FUNDING}

MC is funded by Swansea University Research Excellence Scholarship. Work in the group is supported by Ser Cymru II, Welsh Government.

\section{ACKNOWLEDGMENTS}

MC acknowledges the support from Swansea University Research Excellence Scholarship.

7. França EL, Bitencourt RV, Fujimori M, Cristina de Morais T, de Mattos Paranhos Calderon I, Honorio-França AC. Human colostral phagocytes eliminate enterotoxigenic Escherichia coli opsonized by colostrum supernatant. J Microbiol Immunol Infect (2011) 44:1-7. doi: 10.1016/j.jmii.2011.01.002

8. Zheng Y, Corrêa-Silva S, de Souza EC, Maria Rodrigues R, da Fonseca FAM, Gilio AE, et al. Macrophage profile and homing into breast milk in response to ongoing respiratory infections in the nursing infant. Cytokine (2020) 129:155045. doi: 10.1016/j.cyto.2020.155045

9. Gordon S, Plüddemann A. Tissue macrophages: Heterogeneity and functions. BMC Biol (2017) 15:53. doi: 10.1186/s12915-017-0392-4

10. Sica A, Mantovani A. Macrophage plasticity and polarization: In vivo veritas. J Clin Invest (2012) 122:787-95. doi: 10.1172/JCI59643

11. Jaiswal MK, Mallers TM, Larsen B, Kwak-Kim J, Chaouat G, Gilman-Sachs A, et al. V-ATPase upregulation during early pregnancy: A possible link to establishment of an inflammatory response during preimplantation period of pregnancy. Reproduction (2012) 143:713-25. doi: 10.1530/REP-12-0036

12. Gustafsson C, Mjösberg J, Matussek A, Geffers R, Matthiesen L, Berg G, et al Gene expression profiling of human decidual macrophages: Evidence for immunosuppressive phenotype. PLoS One (2008) 3:e2078. doi: 10.1371/ journal.pone.0002078

13. Yang SW, Cho EH, Choi SY, Lee YK, Park JH, Kim MK, et al. DC-SIGN expression in Hofbauer cells may play an important role in immune 
tolerance in fetal chorionic villi during the development of preeclampsia. J Reprod Immunol (2017) 124:30-7. doi: 10.1016/j.jri.2017.09.012

14. Hamilton S, Oomomian Y, Stephen G, Shynlova O, Tower CL, Garrod A, et al. Macrophages infiltrate the human and rat decidua during term and preterm labor: evidence that decidual inflammation precedes labor1. Biol Reprod (2012) 86:39-40. doi: 10.1095/biolreprod.111.095505

15. Xu Y, Romero R, Miller D, Kadam L, Mial TN, Plazyo O, et al. An M1-like macrophage polarization in decidual tissue during spontaneous preterm labor that Is attenuated by rosiglitazone treatment. J Immunol (2016) 196:2476-91. doi: 10.4049/jimmunol.1502055

16. Aghaeepour N, Ganio EA, Mcilwain D, Tsai AS, Tingle M, Van Gassen S, et al. An immune clock of human pregnancy. Am Assoc Adv Sci (2017) 2: eaan2946. doi: 10.1126/sciimmunol.aan2946

17. Nathan CF, Murray HW, Wlebe IE, Rubin BY. Identification of interferon- $\gamma$, as the lymphokine that activates human macrophage oxidative metabolism and antimicrobial activity. J Exp Med (1983) 158:670-89. doi: 10.1084/ jem.158.3.670

18. Stein M, Keshav S, Harris N, Gordon S. Interleukin 4 potently enhances murine macrophage mannose receptor activity: A marker of alternative immunologic macrophage activation. J Exp Med (1992) 176:287-92. doi: $10.1084 /$ jem.176.1.287

19. Mills CD, Kincaid K, Alt JM, Heilman MJ, Hill AM. M-1/M-2 Macrophages and the Th1/Th2 Paradigm. J Immunol (2000) 164:6166-73. doi: 10.4049/ jimmunol.164.12.6166

20. Xue J, Schmidt SV, Sander J, Draffehn A, Krebs W, Quester I, et al. Transcriptome-Based Network Analysis Reveals a Spectrum Model of Human Macrophage Activation. Immunity (2014) 40:274-88. doi: 10.1016/j.immuni.2014.01.006

21. Martinez FO, Sica A, Mantovani A, Locati M. Macrophage activation and polarization. Front Biosci (2008) 13:453. doi: 10.2741/2692

22. Yao $\mathrm{Y}, \mathrm{Xu} \mathrm{XH}$, Jin L. Macrophage polarization in physiological and pathological pregnancy. Front Immunol (2019) 10:792. doi: 10.3389/ fimmu.2019.00792

23. Viola A, Munari F, Sánchez-Rodríguez R, Scolaro T, Castegna A. The metabolic signature of macrophage responses. Front Immunol (2019) 10:1462. doi: 10.3389/fimmu.2019.01462

24. Wang A, Luan HH, Medzhitov R. An evolutionary perspective on immunometabolism. Science (80- ) (2019) 363:eaar3932. doi: 10.1126/ science.aar3932

25. Sag D, Carling D, Stout RD, Suttles J. Adenosine 5'-monophosphateactivated protein kinase promotes macrophage polarization to an antiInflammatory functional phenotype. J Immunol (2008) 181:8633-41. doi: 10.4049/jimmunol.181.12.8633

26. Muraille E, Leo O, Moser M. Th1/Th2 paradigm extended: Macrophage polarization as an unappreciated pathogen-driven escape mechanism? Front Immunol (2014) 5:603. doi: 10.3389/fimmu.2014.00603

27. Wang F, Zhang S, Jeon R, Vuckovic I, Jiang X, Lerman A, et al. Interferon gamma induces reversible metabolic reprogramming of M1 macrophages to sustain cell viability and pro-inflammatory activity. EBioMedicine (2018) 30:303-16. doi: 10.1016/j.ebiom.2018.02.009

28. Michl J, Ohlbaum DJ, Silverstein SC. 2-Deoxyglucose selectively inhibits fc and complement receptor-mediated phagocytosis in mouse peritoneal macrophages II. Dissociation of the inhibitory effects of 2-deoxyglucose on phagocytosis and atp generation. J Exp Med (1976) 144:1484-93. doi: 10.1084/jem.144.6.1484

29. Haschemi A, Kosma P, Gille L, Evans CR, Burant CF, Starkl P, et al. The sedoheptulose kinase CARKL directs macrophage polarization through control of glucose metabolism. Cell Metab (2012) 15:813-26. doi: 10.1016/ j.cmet.2012.04.023

30. Abuawad A, Mbadugha C, Ghaemmaghami AM, Kim DH. Metabolic characterisation of THP-1 macrophage polarisation using LC-MS-based metabolite profiling. Metabolomics (2020) 16:1-14. doi: 10.1007/s11306020-01656-4

31. Hu L, Yu Y, Huang H, Fan H, Hu L, Yin C, et al. Epigenetic regulation of interleukin 6 by histone acetylation in macrophages and its role in paraquatinduced pulmonary fibrosis. Front Immunol (2017) 7:696. doi: 10.3389/ fimmu.2016.00696
32. Jha AK, Huang SCC, Sergushichev A, Lampropoulou V, Ivanova Y, Loginicheva E, et al. Network integration of parallel metabolic and transcriptional data reveals metabolic modules that regulate macrophage polarization. Immunity (2015) 42:419-30. doi: 10.1016/j.immuni.2015. 02.005

33. Lampropoulou V, Sergushichev A, Bambouskova M, Nair S, Vincent EE, Loginicheva E, et al. Itaconate links inhibition of succinate dehydrogenase with macrophage metabolic remodeling and regulation of inflammation. Cell Metab (2016) 24:158-66. doi: 10.1016/j.cmet.2016.06.004

34. McFadden BA, Purohit S. Itaconate, an isocitrate lyase directed inhibitor in Pseudomonas indigofera. J Bacteriol (1977) 131:136-44. doi: 10.1128/ jb.131.1.136-144.1977

35. Liu PS, Wang H, Li X, Chao T, Teav T, Christen S, et al. $\alpha$-ketoglutarate orchestrates macrophage activation through metabolic and epigenetic reprogramming. Nat Immunol (2017) 18:985-94. doi: 10.1038/ni.3796

36. Ip WKE, Hoshi N, Shouval DS, Snapper S, Medzhitov R. Anti-inflammatory effect of IL-10 mediated by metabolic reprogramming of macrophages. Science (80- ) (2017) 356:513-9. doi: 10.1126/science.aal3535

37. Huang SCC, Everts B, Ivanova Y, O'Sullivan D, Nascimento M, Smith AM, et al. Cell-intrinsic lysosomal lipolysis is essential for alternative activation of macrophages. Nat Immunol (2014) 15:846-55. doi: 10.1038/ni.2956

38. Vats D, Mukundan L, Odegaard JI, Zhang L, Smith KL, Morel CR, et al. Oxidative metabolism and PGC-1 $\beta$ attenuate macrophage-mediated inflammation. Cell Metab (2006) 4:13-24. doi: 10.1016/j.cmet. 2006.05.011

39. Divakaruni AS, Hsieh WY, Minarrieta L, Duong TN, Kim KKO, Desousa BR, et al. Etomoxir Inhibits Macrophage Polarization by Disrupting CoA Homeostasis. Cell Metab (2018) 28:490-503.e7. doi: 10.1016/ j.cmet.2018.06.001

40. Johnson AR, Qin Y, Cozzo AJ, Freemerman AJ, Huang MJ, Zhao L, et al. Metabolic reprogramming through fatty acid transport protein 1 (FATP1) regulates macrophage inflammatory potential and adipose inflammation. Mol Metab (2016) 5:506-26. doi: 10.1016/j.molmet.2016.04.005

41. Namgaladze D, Brüne B. Fatty acid oxidation is dispensable for human macrophage IL-4-induced polarization. Biochim Biophys Acta - Mol Cell Biol Lipids (2014) 1841:1329-35. doi: 10.1016/j.bbalip.2014.06.007

42. Rath M, Müller I, Kropf P, Closs EI, Munder M. Metabolism via arginase or nitric oxide synthase: Two competing arginine pathways in macrophages. Front Immunol (2014) 5:532. doi: 10.3389/fimmu.2014.00532

43. Jena MK, Nayak N, Chen K, Nayak NR. Role of macrophages in pregnancy and related complications. Arch Immunol Ther Exp (Warsz) (2019) 67:295309. doi: 10.1007/s00005-019-00552-7

44. Givan AL, White HD, Stern JE, Colby E, Guyre PM, Wira CR, et al. Flow cytometric analysis of leukocytes in the human female reproductive tract: comparison of fallopian tube, uterus, cervix, and vagina. Am J Reprod Immunol (1997) 38:350-9. doi: 10.1111/j.1600-0897.1997.tb00311.x

45. Hunt JS, Manning LS, Mitchell D, Selanders JR, Wood GW. Localization and Characterization of Macrophages in Murine Uterus. J Leukoc Biol (1985) 38:255-65. doi: 10.1002/jlb.38.2.255

46. Quillay H, El Costa H, Marlin R, Duriez M, Cannou C, Chrétien F, et al. Distinct characteristics of endometrial and decidual macrophages and regulation of their permissivity to HIV-1 infection by SAMHD1. J Virol (2015) 89:1329-39. doi: 10.1128/jvi.01730-14

47. Wira CR, Rodriguez-Garcia M, Patel MV. The role of sex hormones in immune protection of the female reproductive tract. Nat Rev Immunol (2015) 15:217-30. doi: 10.1038/nri3819

48. Bulmer JN, Lunny DP, Hagin SV. Immunohistochemical characterization of stromal leucocytes in nonpregnant human endometrium. Am J Reprod Immunol Microbiol (1988) 17:83-90. doi: 10.1111/j.1600-0897.1988. tb00208.x

49. De M, Wood GW. Influence of oestrogen and progesterone on macrophage distribution in the mouse uterus. J Endocrinol (1990) 126:417-24. doi: $10.1677 /$ joe.0.1260417

50. Bombail V, MacPherson S, Critchley HOD, Saunders PTK. Estrogen receptor related beta is expressed in human endometrium throughout the normal menstrual cycle. Hum Reprod (2008) 23:2782-90. doi: 10.1093/ humrep/den 298 
51. Stewart JA, Bulmer JN, Murdoch AP. Endometrial leucocytes: expression of steroid hormone receptors. J Clin Pathol (1998) 51:121-6. doi: 10.1136/ jcp.51.2.121

52. Wood GW, De M, Sanford T, Choudhuri R. Macrophage colony stimulating factor controls macrophage recruitment to the cycling mouse uterus. Dev Biol (1992) 152:336-43. doi: 10.1016/0012-1606(92)90140-C

53. Okada H, Tsuzuki T, Murata H. Decidualization of the human endometrium. Reprod Med Biol (2018) 17:220-7. doi: 10.1002/rmb2.12088

54. Jensen AL, Collins J, Shipman EP, Wira CR, Guyre PM, Pioli PA. A subset of human uterine endometrial macrophages is alternatively activated. Am J Reprod Immunol (2012) 68:374-86. doi: 10.1111/j.1600-0897.2012.01181.x

55. Eidukaite A, Tamosiunas V. Endometrial and peritoneal macrophages: expression of activation and adhesion molecules. Am J Reprod Immunol (2004) 52:113-7. doi: 10.1111/j.1600-0897.2004.00201.x

56. Schofield G, Kimber SJ. Leukocyte subpopulations in the uteri of leukemia inhibitory factor knockout mice during early pregnancy. Biol Reprod (2005) 72:872-8. doi: 10.1095/biolreprod.104.034876

57. Salamonsen LA, Zhang J, Brasted M. Leukocyte networks and human endometrial remodelling. J Reprod Immunol (2002) 57:95-108. doi: 10.1016/S0165-0378(02)00011-6

58. Salamonsen LA, Woolley DE. Menstruation: Induction by matrix metalloproteinases and inflammatory cells. J Reprod Immunol (1999) 44:1-27. doi: 10.1016/S0165-0378(99)00002-9

59. Singh S, Maniakis-Grivas G, Singh UK, Asher RM, Mauri F, Elkington PT, et al. Interleukin-17 regulates matrix metalloproteinase activity in human pulmonary tuberculosis. J Pathol (2018) 244:311-22. doi: 10.1002/path.5013

60. Zhang J, Hampton AL, Nie G, Salamonsen LA. Progesterone inhibits activation of latent matrix metalloproteinase (MMP)-2 by membrane-type 1 MMP: enzymes coordinately expressed in human endometrium. Biol Reprod (2000) 62:85-94. doi: 10.1095/biolreprod62.1.85

61. Jeziorska M, Nagase H, Salamonsen LA, Woolley DE. Immunolocalization of the matrix metalloproteinases gelatinase B and stromelysin 1 in human endometrium throughout the menstrual cycle. J Reprod Fertil (1996) 107:4351. doi: 10.1530/jrf.0.1070043

62. Yang X, Dong Y, Zhao J, Sun H, Deng Y, Fan J, et al. Increased expression of human macrophage metalloelastase (MMP-12) is associated with the invasion of endometrial adenocarcinoma. Pathol Res Pract (2007) 203:499-505. doi: 10.1016/j.prp.2007.03.008

63. Goffin F, Munaut C, Frankenne F, Perrier d'Hauterive S, Béliard A, Fridman V, et al. Expression pattern of metalloproteinases and tissue inhibitors of matrixmetalloproteinases in cycling human endometrium. Biol Reprod (2003) 69:976-84. doi: 10.1095/biolreprod.103.015933

64. Cousins FL, Kirkwood PM, Saunders PTK, Gibson DA. Evidence for a dynamic role for mononuclear phagocytes during endometrial repair and remodelling. Sci Rep (2016) 6:36748. doi: 10.1038/srep36748

65. Kim SY, Nair MG. Macrophages in wound healing: activation and plasticity. Immunol Cell Biol (2019) 97:258-67. doi: 10.1111/imcb.12236

66. Berbic M, Schulke L, Markham R, Tokushige N, Russell P, Fraser IS. Macrophage expression in endometrium of women with and without endometriosis. Hum Reprod (2009) 24:325-32. doi: 10.1093/humrep/den393

67. Sharkey AM, Day K, McPherson A, Malik S, Licence D, Smith SK, et al. Vascular endothelial growth factor expression in human endometrium Is regulated by hypoxia. J Clin Endocrinol Metab (2000) 85:402-9. doi: 10.1210/ jcem.85.1.6229

68. Crowther M, Brown NJ, Bishop ET, Lewis CE. Microenvironmental influence on macrophage regulation of angiogenesis in wounds and malignant tumors. J Leukoc Biol (2001) 70:478-90. doi: 10.1189/JLB.70.4.478

69. Bacci M, Capobianco A, Monno A, Cottone L, Di Puppo F, Camisa B, et al. Macrophages are alternatively activated in patients with endometriosis and required for growth and vascularization of lesions in a mouse model of disease. Am J Pathol (2009) 175:547-56. doi: 10.2353/ajpath.2009.081011

70. Lawson C, Al-Akoum M, Maheux R, Akoum A. Increased expression of interleukin-1 receptor type 1 in active endometriotic lesions. Reproduction (2007) 133:265-74. doi: 10.1530/rep.1.01121

71. Montagna P, Capellino S, Villaggio B, Remorgida V, Ragni N, Cutolo M, et al. Peritoneal fluid macrophages in endometriosis: correlation between the expression of estrogen receptors and inflammation. Fertil Steril (2008) 90:156-64. doi: 10.1016/j.fertnstert.2006.11.200
72. Chan RWS, Lee C-L, Ng EHY, Yeung WSB. Co-culture with macrophages enhances the clonogenic and invasion activity of endometriotic stromal cells. Cell Prolif (2017) 50:e12330. doi: 10.1111/cpr.12330

73. Akoum A, Metz CN, Al-Akoum M, Kats R. Macrophage migration inhibitory factor expression in the intrauterine endometrium of women with endometriosis varies with disease stage, infertility status, and pelvic pain. Fertil Steril (2006) 85:1379-85. doi: 10.1016/j.fertnstert.2005.10.073

74. Jolicoeur C, Boutouil M, Drouin R, Paradis I, Lemay A, Akoum A. Increased expression of monocyte chemotactic protein-1 in the endometrium of women with endometriosis. Am J Pathol (1998) 152:125-33. doi: 10.1016/ s0015-0282(97)84754-1

75. Symons LK, Miller JE, Kay VR, Marks RM, Liblik K, Koti M, et al. The immunopathophysiology of endometriosis. Trends Mol Med (2018) 24:74862. doi: 10.1016/j.molmed.2018.07.004

76. Jones RL, Hannan NJ, Kaitu'u TJ, Zhang J, Salamonsen LA. Identification of chemokines important for leukocyte recruitment to the human endometrium at the times of embryo implantation and menstruation. J Clin Endocrinol Metab (2004) 89:6155-67. doi: 10.1210/jc.2004-0507

77. Rieger L, Honig A, Sütterlin M, Kapp M, Dietl J, Ruck P, et al. Antigenpresenting cells in human endometrium during the menstrual cycle compared to early pregnancy. J Soc Gynecol Invest (2004) 11:488-93. doi: $10.1016 /$ j.jsgi.2004.05.007

78. Ramhorst R, Grasso E, Paparini D, Hauk V, Gallino L, Calo G, et al. Decoding the chemokine network that links leukocytes with decidual cells and the trophoblast during early implantation. Cell Adh Migr (2016) 10:197207. doi: 10.1080/19336918.2015.1135285

79. Sharkey DJ, Tremellen KP, Jasper MJ, Gemzell-Danielsson K, Robertson SA. Seminal fluid induces leukocyte recruitment and cytokine and chemokine mRNA expression in the human cervix after coitus. J Immunol (2012) 188:2445-54. doi: 10.4049/jimmunol.1102736

80. Robertson SA. Seminal plasma and male factor signalling in the female reproductive tract. Cell Tissue Res (2005) 322:43-52. doi: 10.1007/s00441005-1127-3

81. Gutsche S, von Wolff M, Strowitzki T, Thaler CJ. Seminal plasma induces mRNA expression of IL-1 $\beta$, IL- 6 and LIF in endometrial epithelial cells in vitro. Mol Hum Reprod (2003) 9:785-91. doi: 10.1093/MOLEHR/ GAG095

82. Hunt JS, Manning LS, Wood GW. Macrophages in murine uterus are immunosuppressive. Cell Immunol (1984) 85:499-510. doi: 10.1016/00088749(84)90262-4

83. Houser BL, Tilburgs T, Hill J, Nicotra ML, Strominger JL. Two unique human decidual macrophage populations. J Immunol (2011) 186:2633-42. doi: 10.4049/jimmunol.1003153

84. Repnik U, Tilburgs T, Roelen DL, van der Mast BJ, Kanhai HHH, Scherjon S, et al. Comparison of macrophage phenotype between decidua basalis and decidua parietalis by flow cytometry. Placenta (2008) 29:405-12. doi: $10.1016 /$ j.placenta.2008.02.004

85. Heikkinen J, Mottonen M, Komi J, Alanen A, Lassila O. Phenotypic characterization of human decidual macrophages. Clin Exp Immunol (2003) 131:498-505. doi: 10.1046/j.1365-2249.2003.02092.x

86. Svensson J, Jenmalm MC, Matussek A, Geffers R, Berg G, Ernerudh J. Macrophages at the fetal-maternal interface express markers of alternative activation and are induced by M-CSF and IL-10. J Immunol (2011) 187:3671-82. doi: 10.4049/jimmunol.1100130

87. Lee CL, Guo Y, So KH, Vijayan M, Guo Y, Wong VHH, et al. Soluble human leukocyte antigen G5 polarizes differentiation of macrophages toward a decidual macrophage-like phenotype. Hum Reprod (2015) 30:2263-74. doi: 10.1093/humrep/dev196

88. Smith SD, Dunk CE, Aplin JD, Harris LK, Jones RL. Evidence for immune cell involvement in decidual spiral arteriole remodeling in early human pregnancy. Am J Pathol (2009) 174:1959-71. doi: 10.2353/ajpath.2009. 080995

89. Meinhardt G, Saleh L, Otti GR, Haider S, Velicky P, Fiala C, et al. Wingless ligand $5 \mathrm{a}$ is a critical regulator of placental growth and survival. Sci Rep (2016) 6:28127. doi: 10.1038/srep28127

90. Abrahams VM, Kim YM, Straszewski SL, Romero R, Mor G. Macrophages and apoptotic cell clearance during pregnancy. Am J Reprod Immunol (2004) 51:275-82. doi: 10.1111/j.1600-0897.2004.00156.x 
91. Ding J, Yin T, Yan N, Cheng Y, Yang J. FasL on decidual macrophages mediates trophoblast apoptosis: A potential cause of recurrent miscarriage. Int J Mol Med (2019) 43:2376-86. doi: 10.3892/ijmm.2019.4146

92. Voll RE, Herrmann M, Roth EA, Stach C, Kalden JR, Girkontaite I. Immunosuppressive effects of apoptotic cells. Nature (1997) 390:350-1. doi: $10.1038 / 37022$

93. Osman I. Leukocyte density and pro-inflammatory cytokine expression in human fetal membranes, decidua, cervix and myometrium before and during labour at term. Mol Hum Reprod (2003) 9:41-5. doi: 10.1093/ molehr/gag001

94. Ingman K, Cookson VJKW, Jones CJP, Aplin JD. Characterisation of hofbauer cells in first and second trimester placenta: incidence, phenotype, survival in vitro and motility. Placenta (2010) 31:535-44. doi: 10.1016/ j.placenta.2010.03.003

95. Wynn RM. Derivation and ultrastructure of the so-called Hofbauer cell. Am J Obstet Gynecol (1967) 97:235-48. doi: 10.1016/0002-9378(67)90546-7

96. Kaufmann P, Stark J, Stegner HE. The villous stroma of the human placenta - I. The ultrastructure of fixed connective tissue cells. Cell Tissue Res (1977) 177:105-21. doi: 10.1007/BF00221122

97. Demir R, Kaufmann P, Castelluce M, Erbeng T, Kotowsk A. Fetal vasculogenesis and angiogenesis in human placental villi. Cells Tissues Organs (1989) 136:190-203. doi: 10.1159/000146886

98. Thomas JR, Appios A, Zhao X, Dutkiewicz R, Donde M, Lee CYC, et al. Phenotypic and functional characterization of first-trimester human placental macrophages, Hofbauer cells. J Exp Med (2020) 218:e20200891. doi: $10.1084 / \mathrm{jem} .20200891$

99. Simoni MK, Jurado KA, Abrahams VM, Fikrig E, Guller S. Zika virus infection of hofbauer cells. Am J Reprod Immunol (2017) 77:e12613. doi: $10.1111 /$ aji.12613

100. Kim JS, Romero R, Kim MR, Kim YM, Friel L, Espinoza J, et al. Involvement of Hofbauer cells and maternal $\mathrm{T}$ cells in villitis of unknown aetiology. Histopathology (2008) 52:457-64. doi: 10.1111/j.1365-2559.2008.02964.x

101. Moskalewski S, Ptak W, Czarnik Z. Demonstration of Cells with IgG Receptor in Human Placenta. Neonatology (1975) 26:268-73. doi: 10.1159/ 000240738

102. Toti P, Arcuri F, Tang Z, Schatz F, Zambrano E, Mor G, et al. Focal increases of fetal macrophages in placentas from pregnancies with histological chorioamnionitis: potential role of fibroblast monocyte chemotactic protein-1. Am J Reprod Immunol (2011) 65:470-9. doi: 10.1111/j.16000897.2010.00927.x

103. Castellucci M, Celona A, Bartels H, Steininger B, Benedetto V, Kaufmann P. Mitosis of the Hofbauer cell: Possible implications for a fetal macrophage. Placenta (1987) 8:65-76. doi: 10.1016/0143-4004(87)90040-3

104. Grigoriadis C, Tympa A, Creatsa M, Bakas P, Liapis A, Kondi-Pafiti A, et al. Hofbauer cells morphology and density in placentas from normal and pathological gestations. Rev Bras Ginecol Obstet (2013) 35:407-12. doi: 10.1590/S0100-72032013000900005

105. Kim SY, Romero R, Tarca AL, Bhatti G, Kim CJ, Lee J, et al. Methylome of fetal and maternal monocytes and macrophages at the feto-maternal interface. Am J Reprod Immunol (2012) 68:8-27. doi: 10.1111/j.16000897.2012.01108.x

106. Schliefsteiner C, Peinhaupt M, Kopp S, Lögl J, Lang-Olip I, Hiden U, et al. Human placental hofbauer cells maintain an anti-inflammatory M2 phenotype despite the presence of gestational diabetes mellitus. Front Immunol (2017) 8:888. doi: 10.3389/fimmu.2017.00888

107. Johnson EL, Chakraborty R. Placental Hofbauer cells limit HIV-1 replication and potentially offset mother to child transmission (MTCT) by induction of immunoregulatory cytokines. Retrovirology (2012) 9:101. doi: 10.1186/17424690-9-101

108. Abumaree $\mathrm{MH}, \mathrm{Al}$ Jumah MA, Kalionis B, Jawdat D, Al Khaldi A, Abomaray FM, et al. Human placental mesenchymal stem cells (pMSCs) play a role as immune suppressive cells by shifting macrophage differentiation from inflammatory M1 to anti-inflammatory M2 macrophages. Stem Cell Rev Rep (2013) 9:620-41. doi: 10.1007/s12015-013-9455-2

109. Loegl J, Hiden U, Nussbaumer E, Schliefsteiner C, Cvitic S, Lang I, et al. Hofbauer cells of M2a, M2b and M2c polarization may regulate fetoplacental angiogenesis. Reproduction (2016) 152:447-55. doi: 10.1530/REP16-0159
110. Anteby EY, Natanson-Yaron S, Greenfield C, Goldman-Wohl D, HaimovKochman R, Holzer H, et al. Human placental Hofbauer cells express sprouty proteins: A possible modulating mechanism of villous branching. Placenta (2005) 26:476-83. doi: 10.1016/j.placenta.2004.08.008

111. Demir R, Kayisli UA, Seval Y, Celik-Ozenci C, Korgun ET, Demir-Weusten AY, et al. Sequential expression of VEGF and its receptors in human placental villi during very early pregnancy: Differences between placental vasculogenesis and angiogenesis. Placenta (2004) 25:560-72. doi: 10.1016/ j.placenta.2003.11.011

112. Young OM, Tang Z, Niven-Fairchild T, Tadesse S, Krikun G, Norwitz ER, et al. Toll-like receptor-mediated responses by placental hofbauer cells (HBCs): A potential pro-inflammatory role for fetal M2 macrophages. Am J Reprod Immunol (2015) 73:22-35. doi: 10.1111/aji.12336

113. Akira S, Takeda K, Kaisho T. Toll-like receptors: Critical proteins linking innate and acquired immunity. Nat Immunol (2001) 2:675-80. doi: 10.1038/ 90609

114. Swieboda D, Johnson EL, Beaver J, Haddad L, Enninga EAL, Hathcock M, et al. Baby's first macrophage: temporal regulation of hofbauer cell phenotype influences ligand-mediated innate immune responses across gestation. J Immunol (2020) 204:2380-91. doi: 10.4049/jimmunol.1901185

115. Field CJ. The immunological components of human milk and their effect on immune development in infants. J Nutr (2005) 135:1-4. doi: 10.1093/jn/ 135.1.1

116. Ichikawa M, Sugita M, Takahashi M, Satomi M, Takeshita T, Araki T, et al. Breast milk macrophages spontaneously produce granulocyte-macrophage colony-stimulating factor and differentiate into dendritic cells in the presence of exogenous interleukin-4 alone. Immunology (2003) 108:189-95. doi: 10.1046/j.1365-2567.2003.01572.x

117. Cacho NT, Lawrence RM. Innate immunity and breast milk. Front Immunol (2017) 8:584. doi: 10.3389/fimmu.2017.00584

118. Yamashiro S, Wang JM, Yang D, Gong WH, Kamohara H, Yoshimura T. Expression of CCR6 and CD83 by cytokine-activated human neutrophils. Blood (2000) 96:3958-63. doi: 10.1182/blood.v96.12.3958. h8003958_3958_3963

119. Nagatomo T, Ohga S, Takada H, Nomura A, Hikino S, Imura M, et al. Microarray analysis of human milk cells: Persistent high expression of osteopontin during the lactation period. Clin Exp Immunol (2004) 138:4753. doi: 10.1111/j.1365-2249.2004.02549.x

120. Hughes A, Brock JH, Parrott DM, Cockburn F. The interaction of infant formula with macrophages: effect on phagocytic activity, relationship to expression of class II MHC antigen and survival of orally administered macrophages in the neonatal gut. Immunology (1988) 64:213-8.

121. Riskin A, Almog M, Peri R, Halasz K, Srugo I, Kessel A. Changes in immunomodulatory constituents of human milk in response to active infection in the nursing infant. Pediatr Res (2012) 71:220-5. doi: 10.1038/ pr.2011.34

122. Hassiotou F, Hepworth AR, Metzger P, Tat Lai C, Trengove N, Hartmann $\mathrm{PE}$, et al. Maternal and infant infections stimulate a rapid leukocyte response in breastmilk. Clin Transl Immunol (2013) 2:e3. doi: 10.1038/cti.2013.1

123. Satomi M, Shimizu M, Shinya E, Watari E, Owaki A, Hidaka C, et al. Transmission of macrophage-tropic HIV-1 by breast-milk macrophages via DC-SIGN. J Infect Dis (2005) 191:174-81. doi: 10.1086/426829

124. Henrick BM, Yao X-D, Zahoor MA, Abimiku A, Osawe S, Rosenthal KL. TLR10 senses HIV-1 proteins and significantly enhances HIV-1 infection. Front Immunol (2019) 10:482. doi: 10.3389/fimmu.2019.00482

125. Mcclure EM, Dudley DJ, Reddy U, Goldenberg RL. Infectious causes of stillbirth: A clinical perspective. Clin Obstet Gynecol (2010) 53:635-45. doi: 10.1097/GRF.0b013e3181eb6620

126. Coyne CB, Lazear HM. Zika virus-reigniting the TORCH. Nat Rev Microbiol (2016) 14:707-15. doi: 10.1038/nrmicro.2016.125

127. El Costa H, Gouilly J, Mansuy JM, Chen Q, Levy C, Cartron G, et al. ZIKA virus reveals broad tissue and cell tropism during the first trimester of pregnancy. Sci Rep (2016) 6:35296. doi: 10.1038/srep35296

128. Quicke KM, Bowen JR, Johnson EL, Mcdonald CE, Ma H, O'neal JT, et al. Zika virus infects human placental macrophages. Cell Host Microbe (2016) 20:83-90. doi: 10.1016/j.chom.2016.05.015

129. Schwartz DA. Viral infection, proliferation, and hyperplasia of Hofbauer cells and absence of inflammation characterize the placental pathology of 
fetuses with congenital Zika virus infection. Arch Gynecol Obstet (2017) 295:1361-8. doi: 10.1007/s00404-017-4361-5

130. Jurado KA, Simoni MK, Tang Z, Uraki R, Hwang J, Householder S, et al. Zika virus productively infects primary human placenta-specific macrophages. JCI Insight (2016) 1:e88461. doi: 10.1172/jci.insight.88461

131. Liu X, Jiang M, Ren L, Zhang A, Zhao M, Zhang H, et al. Decidual macrophage $\mathrm{M} 1$ polarization contributes to adverse pregnancy induced by Toxoplasma gondii PRU strain infection. Microb Pathog (2018) 124:183-90. doi: 10.1016/j.micpath.2018.08.043

132. Li Z, Zhao M, Li T, Zheng J, Liu X, Jiang Y, et al. Decidual macrophage functional polarization during abnormal pregnancy due to Toxoplasma gondii: Role for LILRB4. Front Immunol (2017) 8:1013. doi: 10.3389/ fimmu.2017.01013

133. Yui J, Garcia-Lloret M, Wegmann TG, Guilbert LJ. Cytotoxicity of tumour necrosis factor-alpha and gamma-interferon against primary human placental trophoblasts. Placenta (1994) 15:819-35. doi: 10.1016/S01434004(05)80184-5

134. Poston L, Caleyachetty R, Cnattingius S, Corvalán C, Uauy R, Herring S, et al. Preconceptional and maternal obesity: epidemiology and health consequences. Lancet Diabetes Endocrinol (2016) 4:1025-36. doi: 10.1016/ S2213-8587(16)30217-0

135. National Maternity and Perinatal Audit. (2019). Available at: www.hqip.org. $\mathrm{uk} /$ national-programmes [Accessed June 10, 2020].

136. Zatterale F, Longo M, Naderi J, Raciti GA, Desiderio A, Miele C, et al. Chronic adipose tissue inflammation linking obesity to insulin resistance and type 2 diabetes. Front Physiol (2020) 10:1607. doi: 10.3389/fphys.2019.01607

137. Oróstica L, Astorga I, Plaza-Parrochia F, Vera C, García V, Carvajal R, et al. Proinflammatory environment and role of TNF- $\alpha$ in endometrial function of obese women having polycystic ovarian syndrome. Int J Obes (2016) 40:1715-22. doi: 10.1038/ijo.2016.154

138. Templeman C, Marshall SF, Ursin G, Horn-Ross PL, Clarke CA, Allen M, et al. Adenomyosis and endometriosis in the California Teachers Study. Fertil Steril (2008) 90:415-24. doi: 10.1016/j.fertnstert.2007.06.027

139. Trabert B, Weiss NS, Rudra CB, Scholes D, Holt VL. A Case-Control Investigation of Adenomyosis: Impact of Control Group Selection on Risk Factor Strength. Womens Health Issues (2011) 21:160-4. doi: 10.1016/ j.whi.2010.09.005

140. Tremellen KP, Russell P. The distribution of immune cells and macrophages in the endometrium of women with recurrent reproductive failure. II: Adenomyosis and macrophages. J Reprod Immunol (2012) 93:58-63. doi: 10.1016/j.jri.2011.12.001

141. Challier JC, Basu S, Bintein T, Minium J, Hotmire K, Catalano PM, et al. Obesity in pregnancy stimulates macrophage accumulation and inflammation in the placenta. Placenta (2008) 29:274-81. doi: 10.1016/ j.placenta.2007.12.010

142. Roberts KA, Riley SC, Reynolds RM, Barr S, Evans M, Statham A, et al. Placental structure and inflammation in pregnancies associated with obesity. Placenta (2011) 32:247-54. doi: 10.1016/j.placenta.2010.12.023

143. Becroft DM, Thompson JM, Mitchell EA. Placental villitis of unknown origin: Epidemiologic associations. Am J Obstet Gynecol (2005) 192:264-71. doi: 10.1016/j.ajog.2004.06.062

144. Koga K, Mor G. Toll-Like receptors at the maternal-fetal interface in normal pregnancy and pregnancy disorders. Am J Reprod Immunol (2010) 63:587600. doi: 10.1111/j.1600-0897.2010.00848.x

145. Yang X, Haghiac M, Glazebrook P, Minium J, Catalano PM, Hauguel-de Mouzon S. Saturated fatty acids enhance TLR4 immune pathways in human trophoblasts. Hum Reprod (2015) 30:2152-9. doi: 10.1093/ humrep/dev173

146. Rogers LM, Serezani CH, Eastman AJ, Hasty AH, Englund-Ögge L, Jacobsson B, et al. Palmitate induces apoptotic cell death and inflammasome activation in human placental macrophages. Placenta (2020) 90:45-51. doi: 10.1016/j.placenta.2019.12.009

147. Milanski M, Degasperi G, Coope A, Morari J, Denis R, Cintra DE, et al. Saturated fatty acids produce an inflammatory response predominantly through the activation of TLR4 signaling in hypothalamus: Implications for the pathogenesis of obesity. J Neurosci (2009) 29:359-70. doi: 10.1523/ JNEUROSCI.2760-08.2009
148. Laskewitz A, van Benthem KL, Kieffer TEC, Faas MM, Verkaik-Schakel RN, Plösch T, et al. The influence of maternal obesity on macrophage subsets in the human decidua. Cell Immunol (2019) 336:75-82. doi: 10.1016/ j.cellimm.2019.01.002

149. Sibai BM. Diagnosis and management of gestational hypertension and preeclampsia. Obstet Gynecol (2003) 102:181-92. doi: 10.1016/S0029-7844 (03)00475-7

150. Sierra-Laguado J, García RG, Celedón J, Arenas-Mantilla M, Pradilla LP, Camacho PA, et al. Determination of insulin resistance using the homeostatic model assessment (HOMA) and its relation with the risk of developing pregnancy-induced hypertension. Am J Hypertens (2007) 20:43742. doi: 10.1016/j.amjhyper.2006.10.009

151. Palei AC, Spradley FT, Granger JP. Euglycemic hyperinsulinemia increases blood pressure in pregnant rats independent of placental antiangiogenic and inflammatory factors. Am J Hypertens (2013) 26:1445-51. doi: 10.1093/ajh/ hpt137

152. Lopez-Jaramillo P, Barajas J, Rueda-Quijano SM, Lopez-Lopez C, Felix C. Obesity and preeclampsia: common pathophysiological mechanisms. Front Physiol (2018) 9:1838. doi: 10.3389/fphys.2018.01838

153. Pavan L, Hermouet A, Tsatsaris V, Thérond P, Sawamura T, Evain-Brion D, et al. Lipids from oxidized low-density lipoprotein modulate human trophoblast invasion: Involvement of nuclear liver $\mathrm{X}$ receptors. Endocrinology (2004) 145:4583-91. doi: 10.1210/en.2003-1747

154. Reister F, Frank HG, Heyl W, Kosanke G, Huppertz B, Schröder W, et al. The distribution of macrophages in spiral arteries of the placental bed in preeclampsia differs from that in healthy patients. Placenta (1999) 20:229-33. doi: $10.1053 /$ plac. 1998.0373

155. Petsas G, Jeschke U, Richter DU, Minas V, Hammer A, Kalantaridou S, et al. Aberrant expression of corticotropin-releasing hormone in pre-eclampsia induces expression of FasL in maternal macrophages and extravillous trophoblast apoptosis. Mol Hum Reprod (2012) 18:535-45. doi: 10.1093/ molehr/gas 027

156. Neale D, Demasio K, Illuzi J, Chaiworapongsa T, Romero R, Mor G. Maternal serum of women with pre-eclampsia reduces trophoblast cell viability: Evidence for an increased sensitivity to Fas-mediated apoptosis. J Matern Fetal Neonatal Med (2003) 13:39-44. doi: 10.1080/jmf.13.1.39.44

157. Reister F, Frank HG, Kingdom JCP, Heyl W, Kaufmann P, Rath W, et al. Macrophage-induced apoptosis limits endovascular trophoblast invasion in the uterine wall of preeclamptic women. Lab Invest (2001) 81:1143-52. doi: 10.1038/labinvest.3780326

158. Huang SJ, Zenclussen AC, Chen CP, Basar M, Yang H, Arcuri F, et al. The implication of aberrant GM-CSF expression in decidual cells in the pathogenesis of preeclampsia. Am J Pathol (2010) 177:2472-82. doi: 10.2353/ajpath.2010.091247

159. Li M, Piao L, Chen CP, Wu X, Yeh CC, Masch R, et al. Modulation of decidual macrophage polarization by macrophage colony-stimulating factor derived from first-trimester decidual cells: implication in preeclampsia. Am J Pathol (2016) 186:1258-66. doi: 10.1016/j.ajpath.2015.12.021

160. Morais TC, Honorio-França AC, Fujimori M, de Quental OB, Pessoa RS, França EL, et al. Melatonin Action on the Activity of Phagocytes from the Colostrum of Obese Women. Medicina (B Aires) (2019) 55:625. doi: 10.3390/ medicina55100625

161. Morais TC, de Abreu LC, de Quental OB, Pessoa RS, Fujimori M, Daboin BEG, et al. Obesity as an Inflammatory Agent Can Cause Cellular Changes in Human Milk due to the Actions of the Adipokines Leptin and Adiponectin. Cells (2019) 8:519. doi: 10.3390/cells8060519

162. Marufu TC, Ahankari A, Coleman T, Lewis S. Maternal smoking and the risk of still birth: systematic review and meta-analysis. BMC Public Health (2015) 15:239. doi: 10.1186/s12889-015-1552-5

163. Rua E de AO, Porto ML, Ramos JPL, Nogueira BV, dos Santos Meyrelles S, Vasquez EC, et al. Effects of tobacco smoking during pregnancy on oxidative stress in the umbilical cord and mononuclear blood cells of neonates. J BioMed Sci (2014) 21:105. doi: 10.1186/s12929-014-0105-z

164. Belhareth R, Mezouar S, Ben Amara A, Chartier C, Ben Azzouz E, Chabrière E, et al. Cigarette smoke extract interferes with placenta macrophage functions: A new mechanism to compromise placenta functions? Reprod Toxicol (2018) 78:120-9. doi: 10.1016/j.reprotox.2018.04.009 
165. Olsson D, Mogren I, Forsberg B. Air pollution exposure in early pregnancy and adverse pregnancy outcomes: A register-based cohort study. BMJ Open (2013) 3:e001955. doi: 10.1136/bmjopen-2012-001955

166. Korten I, Ramsey K, Latzin P. Air pollution during pregnancy and lung development in the child. Paediatr Respir Rev (2017) 21:38-46. doi: 10.1016/ j.prrv.2016.08.008

167. Bové H, Bongaerts E, Slenders E, Bijnens EM, Saenen ND, Gyselaers W, et al. Ambient black carbon particles reach the fetal side of human placenta. Nat Commun (2019) 10:3866. doi: 10.1038/s41467-019-11654-3

168. Liu N, Miyashita L, Mcphail G, Thangaratinam S, Grigg J. Late Breaking Abstract - Do inhaled carbonaceous particles translocate from the lung to the placenta? Eur Respir J (2018) 52:PA360. doi: 10.1183/13993003.congress-2018.pa360

169. Familari M, Nääv Å, Erlandsson L, de Iongh RU, Isaxon C, Strandberg B, et al. Exposure of trophoblast cells to fine particulate matter air pollution leads to growth inhibition, inflammation and ER stress. PLoS One (2019) 14: e0218799. doi: 10.1371/journal.pone.0218799

170. Bekki K, Ito T, Yoshida Y, He C, Arashidani K, He M, et al. PM 2.5 collected in China causes inflammatory and oxidative stress responses in macrophages through the multiple pathways. Environ Toxicol Pharmacol (2016) 45:362-9. doi: 10.1016/j.etap.2016.06.022

171. Ferguson KK, McElrath TF, Meeker JD. Environmental phthalate exposure and preterm birth. JAMA Pediatr (2014) 168:61-7. doi: 10.1001/ jamapediatrics.2013.3699

172. Mose T, Mortensen GK, Hedegaard M, Knudsen LE. Phthalate monoesters in perfusate from a dual placenta perfusion system, the placenta tissue and umbilical cord blood. Reprod Toxicol (2007) 23:83-91. doi: 10.1016/ j.reprotox.2006.08.006

173. Tetz LM, Aronoff DM, Loch-Caruso R. Mono-ethylhexyl phthalate stimulates prostaglandin secretion in human placental macrophages and THP-1 cells. Reprod Biol Endocrinol (2015) 13:56. doi: 10.1186/s12958-015-0046-8
174. Nickerson K. Environmental contaminants in breast milk. J Midwifery Womens Health (2006) 51:26-34. doi: 10.1016/j.jmwh.2005.09.006

175. Mores L, França EL, Silva NA, Suchara EA, Honorio-França AC. Nanoparticles of barium induce apoptosis in human phagocytes. Int $J$ Nanomedicine (2015) 10:6021-6. doi: 10.2147/IJN.S90382

176. Thangavel J, Samanta S, Rajasingh S, Barani B, Xuan YT, Dawn B, et al. Epigenetic modifiers reduce inflammation and modulate macrophage phenotype during endotoxemia-induced acute lung injury. J Cell Sci (2015) 128:3094-105. doi: 10.1242/jcs. 170258

177. Liu RT, Zhang M, Yang CL, Zhang P, Zhang N, Du T, et al. Enhanced glycolysis contributes to the pathogenesis of experimental autoimmune neuritis. J Neuroinflammation (2018) 15:51. doi: 10.1186/s12974-018-1095-7

178. Kornberg MD, Bhargava P, Kim PM, Putluri V, Snowman AM, Putluri N, et al. Dimethyl fumarate targets GAPDH and aerobic glycolysis to modulate immunity. Science (80- ) (2018) 360:449-53. doi: 10.1126/science.aan4665

179. Wenes M, Shang M, Di Matteo M, Goveia J, Martín-Pérez R, Serneels J, et al. Macrophage metabolism controls tumor blood vessel morphogenesis and metastasis. Cell Metab (2016) 24:701-15. doi: 10.1016/j.cmet.2016.09.008

Conflict of Interest: The authors declare that the research was conducted in the absence of any commercial or financial relationships that could be construed as a potential conflict of interest.

Copyright (C) 2021 Chambers, Rees, Cronin, Nair, Jones and Thornton. This is an open-access article distributed under the terms of the Creative Commons Attribution License (CC BY). The use, distribution or reproduction in other forums is permitted, provided the original author(s) and the copyright owner(s) are credited and that the original publication in this journal is cited, in accordance with accepted academic practice. No use, distribution or reproduction is permitted which does not comply with these terms. 